\title{
Description and taxonomic analysis of a tuberculated turtle leech from the Outer Banks, North Carolina, USA, provisionally identified as Placobdella multilineata Moore, 1953 (Hirudinea: Glossiphoniidae)
}

\author{
ROY T. SAWYER \\ Medical Leech Museum, 2 Bryngwili Road, Hendy, Pontarddulais, Swansea SA4 OXT, UK \\ "leechmuseum@compuserve.com; ○ https://orcid.org/0000-0001-8461-0380
}

\begin{abstract}
A tuberculated species of turtle leech is indigenous to the Great Dismal Swamp and environs of northeastern North Carolina, and differs from other known species of Placobdella. This study of hundreds of specimens for more than a decade documents its unexpected taxonomic complexity. In fact, this seemingly innocuous leech undergoes radical transformations in terms of morphology and behaviour, each adapted to a different phase of its life cycle. Biological observations reveal a progressive darkening with age which imposes taxonomic uncertainties. Furthermore, some commonly used characters are found to be unsound for taxonomic diagnosis in that they do not occur in all individuals of this species. The primary objective of this paper is a comprehensive description of this Albemarle turtle leech. The question is then asked, what distinguishes it from allied species? Toward this end, a formal taxonomic diagnosis is proposed based on details of the proboscis complex and crop-related tuberculation. This species is allied to the northern P. rugosa (Verrill, 1874) or its southern counterpart $P$. multilineata Moore, 1953. However, synonymy to either of these forms is problematical due to inadequacy of type descriptions. Nonetheless, in view of habitat similarity the Albemarle leech is provisionally identified as $P$. multilineata pending comparable studies of variability and development of other tuberculated Placobdella.
\end{abstract}

Key words: Accessory eye, mycetome, hollensis, parasitica, rugosa, turtle parasite

\section{Introduction}

The Albemarle-Pamlico region of the Outer Banks of northeastern North Carolina and southeastern Virginia is one of the largest wetlands in the United States (Sawyer 2010). This ancient, residual swampland is of biogeographic significance in that it is at the northern tip of a warm coastal strip where the Gulf Stream leaves the American continent (Fig. 1A). Of biological significance for this paper this unique biome abounds with some of the greatest numbers and kinds of turtles in North America (Palmer \& Braswell 2013; Meyers \& Pike 2006).

The most conspicuous bloodsucking leech in these blackwater swamps is a relatively large tuberculated species of Placobdella typically encountered on the snapping turtle Chelydra serpentina (Linnaeus). Although this leech is common in the Albemarle region its identification is indeterminate in that it differs in detail from the more than twenty nominal species of Placobdella reported from North America (Moser et al. 2016; de Carle et al. 2017). However, designation of a new species of Placobdella is not justified at this time for the reasons discussed below.

Biological observations for more than a decade gradually revealed that the taxonomy of this seemingly innocuous species is actually quite complex due to a high degree of phenotypic plasticity. In fact, this Albemarle turtle leech is surprisingly variable, in part because it undergoes radical transformations in terms of morphology and behaviour, each adapted to a different phase of its life cycle.

The hundreds of specimens collected in this long-term study range from transparent, to variegated, to uniformly dark brown, depending primarily on age. In fact, during growth and development there is a progressive darkening such that stripes and patterns are initially silhouetted, and then with age become obfuscated, adding to taxonomic uncertainty. This progressive increase in pigmentation is probably attributable to life-time accumulation of breakdown products of turtle blood. 
The primary objective of this paper is a comprehensive description of this Albemarle turtle leech. The question is then asked, what distinguishes this leech from the twenty or so other species of Hirudinea known from the Albemarle region? Methodologically, this study focuses on a critical assessment of potential taxonomic characters in order to identify foremost those which can rigorously diagnose this species. Such diagnostic characters are defined as those which occur in all individuals of this species, but do not occur in other species in the region. Moreover, those characters found in some, but not all, individuals of this species are relegated as unsound for taxonomic diagnosis. By way of summary, this study proposes that three invariant characters diagnose this species even from the hatchling stage, i.e., they collectively distinguish it from all other species in the region.

Whether the Albemarle turtle leech as diagnosed herein is endemic to the Albemarle region remains a possibility. On balance, however, it is more likely allied to, or conspecific with, a species of tuberculated Placobdella already described. In this context possible candidates are two well known turtle leeches, the northern P. rugosa (Verrill, 1874) or its apparent southern counterpart P. multilineata Moore, 1953, both of which generally resemble the Albemarle leech. Unfortunately, however, synonymy to either of these forms is problematical due to inadequacy of original descriptions from type material.

\section{Materials and methods}

\section{Methodology}

This study integrates morphology, development and biology to explore and extend the taxonomy of this indeterminate species which, for convenience, is hereafter referred to as the Albemarle turtle leech, or simply Albemarle leech.

Archetype. In keeping with established taxonomic principles a single representative individual is described in detail. The designation of an archetype stabilises nomenclature in the event that the provisional identification of this species proves not to be $P$. multilineata, or that a similar, but cryptic, species also lives in the Albemarle region.

Variability. An abundant series of specimens from disparate parts of the Albemarle region constitutes a sound basis for examining population and geographic variation within this species. Toward this end the aforementioned archetype serves as a standard reference or baseline against which variation is assessed for the purposes of this study. The guiding principle throughout this analysis is that highly variable characters are considered taxonomically unreliable for diagnosing this species. Conversely, highly conserved traits are deemed characteristic of, or even specific to, this species.

Developmental taxonomy. An untapped aspect of variability of leech species generally is the degree of change they undergo during growth and development. Accordingly, in this study chronology of selected characters during development is followed with the view of giving perspective to their roles in the architecture of the adult. It is shown that the timing, mechanism and function of a character during development can strengthen or lessen its taxonomic significance.

In this study a large series of embryonic and juvenile specimens provides a rare, possibly unique, opportunity to explore this ontogenetic dimension of the taxonomy of this species. This approach raises novel questions. For example, when in development can the Albemarle leech be recognised as distinct from all other leech species in the region? Which taxonomic characters arise early, or late, in development, and the biological and phylogenetic implications thereof? Indeed, it is shown in this study that some seemingly significant characters can disappear during development.

These developmental observations are confined to the phenotype of the Albemarle turtle leech. An understanding of underlying genomic factors lies outside the scope of this paper (see Lafuente \& Beldade 2019). Furthermore, this study does not address the adaptive or evolutionary interactions of the environment with the genome of this species (Galtier et al. 2009).

Outgroup. A taxonomic question asked throughout this paper is whether a particular character expressed in the Albemarle turtle leech is also found in at least one allied species in this geographic region. In this context the most relevant outgroup species is the congener Placobdella parasitica (Say), a non-tuberculated turtle leech. Although widely distributed in much of the United States (Whitman 1891; Moser et al. 2013; Richardson et al. 2020), only three adults of this species were encountered in the Albemarle region in the 13 years of this study (see Appendix). All three are dissected (PP-1, $36.5 \mathrm{~mm}$; PP-2, $22.0 \mathrm{~mm}$; PP-4a, $39.8 \mathrm{~mm}$ ), and the largest of these (PP-4a) is selected 
as an archetype specimen for detailed assessment of external and internal characters. The remaining specimens, including a juvenile (PP-3, $12.8 \mathrm{~mm}$ ), serve for evaluation of variability. In addition, morphological changes during development are examined in recent unfed hatchings $(\mathrm{PP}-4 \mathrm{~b}$, averaging $6.0 \mathrm{~mm}$ ). Taken together these outgroup specimens demonstrate the paramount taxonomic importance of the foregut, and reveal unexpected loss of turberculation during development in the outgroup species.

\section{Resource material}

This study is based entirely on specimens collected by the author and colleagues from 2008 to 2020 in the Albemarle-Pamlico region of the Outer Banks, NC. It does not include museum specimens collected and preserved by others, nor specimens from outside this region.

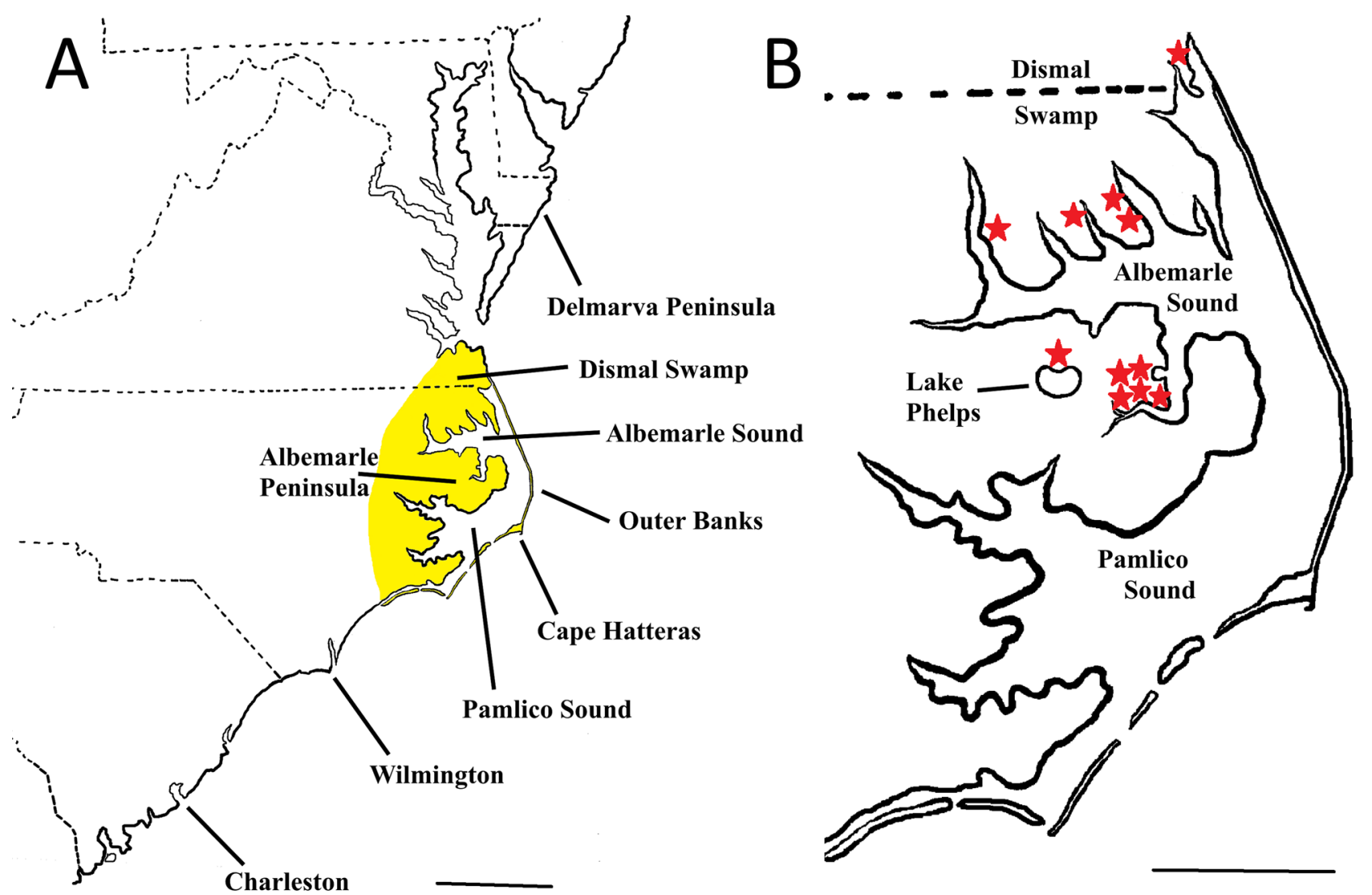

FIGURE 1. A, Map of the mid-Atlantic coastal plain showing location of the Albemarle region of the Outer Banks, North Carolina, USA. This wetlands (yellow shading) is the focus of an ongoing study of the Hirudinea. B, Close-up of locality stations (red stars) where over 675 Albemarle turtle leeches were collected in this study from 2008-2020. See Appendix for compilation of locality records. Scale bars: A, $100 \mathrm{~km} ; \mathrm{B}, 50 \mathrm{~km}$.

ABBREVIATIONS TO FIGURES. a, atrium; ae, accessory eye; ah, atrial horn; an, anus; b, 'brain'; cc, crop caecum; cl, 'colossal cells'; cu, detached cuticle; cup, detached cuticle of proboscis sheath; e, eye; ed, ejaculatory duct; f, female gonopore; g, ganglion; ic, intestinal caecum; lp, lateral head patch of segment IV; m, male gonopore; ma, metameric marginal pattern; mp, mouth pore; my, mycetome; oc, common ovisac; oe, oesophagus; op, posterior arm of ovisac; ov, vertical arm of ovisac; $p$, proboscis; pa, point of attachment; pb, base of proboscis; pd, paramedial stripe; pm, protractor muscle; pp, placobdellid head pattern; ps, proboscis sheath; pt, pre-anal tubercle; r, rectum; rm, retractor muscle; s, mid-dorsal stripe; sa, anterior salivary 'gland'; sb, common bundle of ductules from both salivary 'glands'; sd, bundle of ductules from salivary 'gland'; sp, posterior salivary 'gland'; pst, presumptive salivary tissue; sv, seminal vesicle; t2, second testisac; ta, paramarginal tubercle; ti, intermediate tubercle; tm, medial tubercle; tp, paramedial tubercle; ua, pre-ocular unpigmented area; vr, ventral rim of oral sucker; vs, ventral longitudinal stripe; wp, white patch.

A total of 676 individuals of this species were examined alive, prior to preservation. These comprised 33 brooding/gravid adults (4.9\%), 128 free-living juveniles (19.9\%) and 515 brooded embryos (76.2\%). They were collected in disparate parts of the Albemarle region, primarily north and south of the Albemarle Sound (Fig.1B). They repre- 
sent 11 collecting stations in 6 counties and 2 states. The annotated locality records are compiled in the Appendix. All specimens are deposited either in the Medical Leech Museum under the rubric (PM), or in the US National Museum (USNM).

To assist future workers, individual leeches specifically mentioned in the narrative to make a particular point are cited by their unique reference numbers in the Appendix.

\section{Collecting techniques}

Traditional hand-collecting grossly under-represents the abundance of this species in the Albemarle region in that most habitats are inaccessible or inherently hazardous in these frequently impenetrable swamps, not only from deep mud, but also from venomous animals (Fig. 2A). A breakthrough, without which this study would not have been possible in its current form, was the fabrication of a specialised device specifically designed to attract leeches inhabiting this otherwise inhospitable environment (Fig. 2B). This apparatus exploits the well-known observations that leeches, as suckered animals, are 'super-adapted' to smooth surfaces, and have a propensity toward dark surroundings.

This device, named 'Essig' leech trap in recognition of its developer (see Acknowledgments), consists of an aluminium sheet which has been folded into a rectangle (roughly $14 \times 23 \mathrm{~cm}$ ) to form a dark, 'cosy' pocket with smooth inner and outer surfaces throughout. This trap is attached by a nylon cord such that it can be laid or thrown onto the muddy bottom, or amongst aquatic vegetation, to be retrieved overnight. The majority of leeches in this study were collected by means of these leech traps, in some cases in the same locality for many consecutive years of this study. Others were hand collected in shallow water using waders to examine submerged logs and limbs, aquatic vegetation, and submerged plastic and glass. Most turtles encountered on land were examined for leeches. Unfortunately, no attempt was made to trap aquatic turtles routinely.
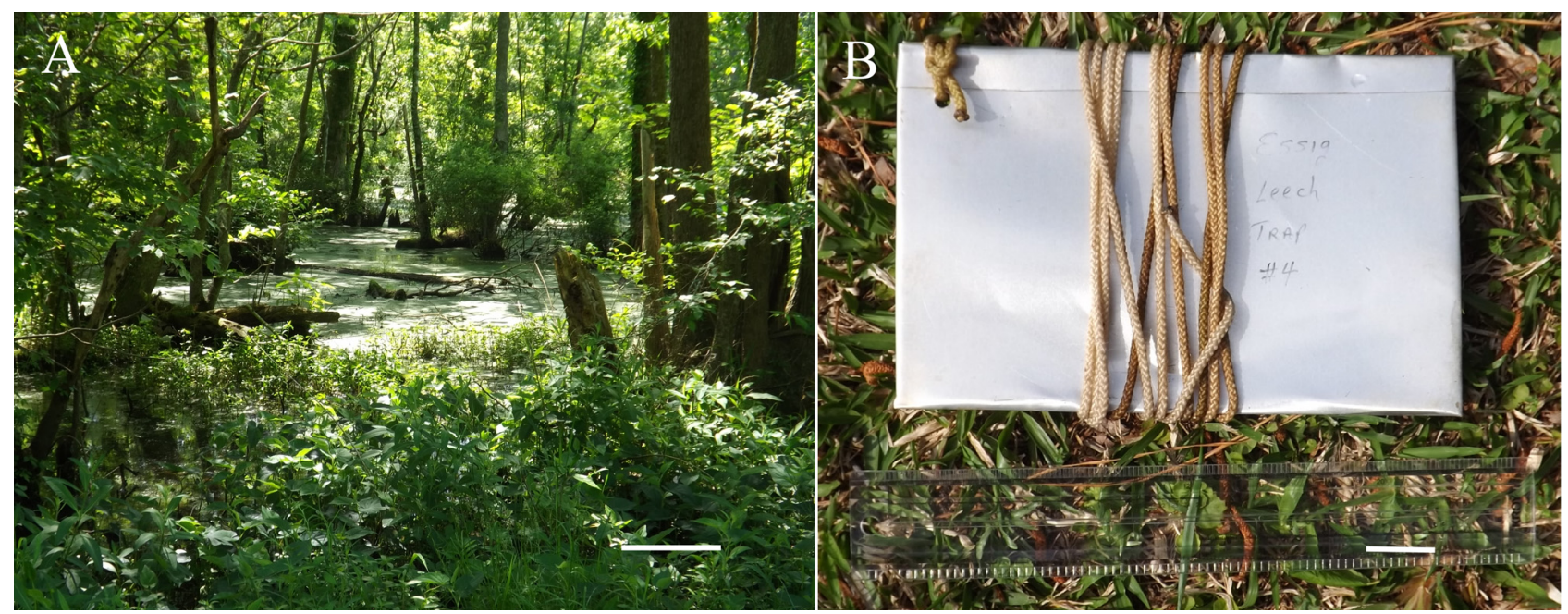

FIGURE 2. A, Typical swamp habitat for the Albemarle turtle leech. Shown is Griffin Swamp, Pasquotank County, NC, where 8 specimens (4.5-44 mm) were collected overnight by means of the 'Essig' leech trap shown in B (see Methods). B, This pocketed, aluminium device transforms sampling leeches in such inhospitable swamps. Scale bars: A, $1 \mathrm{~m} ; \mathrm{B}, 2.5 \mathrm{~cm}$.

\section{Collecting bias}

Future workers should be aware of potential seasonal, geographic and collecting bias in this study. For logistical reasons field collecting was centred in the month of May (March-June) each year. This is the peak breeding season which ensured a plentiful supply of mature adults on which a secure taxonomy is based. Unfortunately, no collecting was carried out during the winter months (November to February, inclusively).

The majority of specimens were collected in southern Tyrrell County in the Albemarle Peninsula because the community of Gum Neck was the base for field operations for each of the thirteen years of this study. While this is the geographic centre of the Albemarle region, every effort was made to collect more widely.

\section{Preservation and dissection}

Special care must be taken in handling this species in that pigmented features so evident in life can be significantly obscured following preservation. As a safeguard, specimens should be photographed in life prior to preservation. 
In a minimum quantity of water the living specimen is relaxed gradually by adding a few drops of alcohol at intervals until no movement is detectable upon prodding. As a further precaution against contraction, the narcotised specimen is then put under hot water for a further few minutes. After removing mucus with a damp paper towel, the deceased specimen is laid out without stretching in a wax-bottomed dissecting tray and carefully flooded with $5 \%$ formalin. It is undesirable to use insect pins through the tissue to secure the specimen in position. After several hours the specimen is then stored in 5\% formalin in preference to $10 \%$ formalin (which makes the tissue brittle for dissection) or $70 \%$ alcohol (which dissolves pigmentation).

Microscopic examination of external features is carried out in a wax-bottomed dissecting tray using a Wild M7A stereo microscope with a Volpi Intralux 4000 light source, assisted by a Lapsun Spot Point LED lamp with ultraviolet option. Images were taken with digital cameras of increasing magnification: a) Conrad Electrics, Mirazoon MZ902, DP-M14; b) Yuanj MC500 eyepiece camera for stereo microscope; and c) Bresser LCD 5 MP microscope for prepared slides. Measurements are made by an Ocular Micrometer Model WF 10X. All images in this paper depict only this turtle leech from the Albemarle region.

Extensive use of several hundred digital photographs constitute a crucial part of the methodology in that such imagery is invaluable in analysing variation of external features among specimens. Each adult is photographed dorsally and ventrally, including close-up images of the head and caudal regions. By being able to compare digital features side by side with segmental precision greatly minimises subjectivity.

Internal anatomy in particular advances the taxonomic understanding of this species. Toward this end the digestive and reproductive systems of six adult specimens $(32-44 \mathrm{~mm}$ ) from disparate localities are dissected as follows. In a wax-bottomed dissecting tray containing dechlorinated water each specimen is positioned dorsal side up. The caudal sucker is secured by a single insect pin, and the mid-body is pinned through the tissue near the lateral margins on either side. The neck region is secured tightly by overlapping pins into the wax on either side, not through the tissue. An initial transverse incision is made mid-body starting at the dorsal mid-line. This shallow incision is continued by fine scissors along a furrow toward the margins on either side. Near the margins the incision is directed anteriorly parallel to the sides, gradually teasing away connective tissue just under the skin. The resultant flap is generated anteriorly until the underlying digestive and reproductive structures are exposed. During the dissection process, photographic images are desirable at appropriate stages for future reference and comparison. Printed images serve as outline for line drawings of the digestive and reproductive systems.

\section{Segmentation and annulation}

Details of segmentation and annulation are of great taxonomic significance for this species at all stages of development. The terminology used throughout this paper follows that conventionally recognized throughout the Hirudinea (see Sawyer 1986: 54-66). By way of summary, this species, as in all Hirudinea, is comprised of 34 segments, each assigned a Roman numeral (I-XXXIV). Each segment is defined by its respective ganglion. The head is comprised of six fused ganglia (I-VI), and the caudal sucker is comprised of seven fused ganglia (XXVIII-XXXIV). The intervening 21 body segments (VII-XXVII) are linked by the ventral nerve cord, a chain of 21 consecutive ganglia. In this paper the words ganglion and segment are abbreviated, followed by the respective Roman numeral. For example, ganglion eighteen is written "g. XVIII", and its respective segment is written "s. XVIII" or simply XVIII. In most images segmental landmarks are indicated for reference, with emphasis on segments VII, XIII and XIX, respectively.

In this species each mid-body segment is comprised of three encircling annuli, designated from anterior to posterior as a1, a2 and a3, respectively. Thus, the designation XIa3/XIIa1 refers to the furrow between the third annulus of segment XI and the first annulus of segment XII. Similarly, XIIa2/a3 refers to the furrow between the second and third annuli of segment XII. These are the respective locations of the male and female gonopores and serve as invariant landmarks at the ventral mid-line of this species.

In the head and caudal regions the segmental annulation is truncated. For example, segment IV consists of only two annuli, a larger barely sub-divided anterior annulus designated IV $(\mathrm{a} 1+\mathrm{a} 2)$ followed by annulus IVa3.

The middle annulus, a2, of a mid-body segment is recognised as the centre of that segment, defined internally as the location of the respective ganglion. The 22 annulus on the dorsum bears the largest of metamerically repeated tubercles, invariably located in the intermediate position in this species. The arrangement of tubercles on the respective annuli in a segment is taxonomically and developmentally significant in this species. 


\section{Terminology}

Taxonomic terminology generally follows that of Dubois (2017). Most importantly for this study, the term 'diagnosis' is used in this paper to refer to those characters which singly or in combination are found in all post-hatching individuals of the Albemarle turtle leech, but are not found in allied species in this region.

The term 'character' is used throughout this paper to mean any trait of this species which can potentially distinguish it from other species in the Albemarle region. A character can refer to pigmentation, anatomy, development, behaviour or biology. Importantly, a distinction is made between those characters which are characteristic of this species from those which are specific to this species in this region. For example, a round caudal sucker is characteristic of the Albemarle turtle leech, but it is not specific to this species in that other species also share this character.

In this paper the term 'tubercle' is used in preference to 'papilla' or 'sensilla' without comment with regard to any cytological distinction or function. Tubercles as observed in this species are small to medium, rounded structures well raised from the tegument and potentially on any dorsal annulus. 'Peduncle' is used in preference to 'pedicel'. Salivary 'gland' is used for convenience. They are not true glands with a lumen as in vertebrates but are actually an aggregation of salivary cells each with a separate ductule leading into the proboscis. In the context of pigment patterns mention is made of large cream-coloured cells associated with unpigmented areas. For convenience these are termed 'colossal cells' without prejudice as to their cytology or function.

\section{Results}

\section{Description of archetype of the Albemarle turtle leech}

A single adult specimen (PM-14d) is selected as being representative of the Albemarle turtle leech (Fig. 3). Its external features are described in detail in this section to serve as a reference or baseline against which comparisons can be made with regard to population and geographic variability in this region. Description of internal features is based on dissection of a different specimen (PM-1b) from the same series.

\section{External features}

Dorsum (Fig. 3A). The specimen was preserved in relaxed position with its head very slightly raised. The body is remarkably flat, opaque and lance-shaped. Its maximum width is at segment XVII in the posterior half of the body. From this point the body gradually narrows anteriorly. The margins are smooth with regular, uniform annuli throughout its length. The dorsal surface is tuberculated but not conspicuously so from any distance. Its dimensions are: length, $28.0 \mathrm{~mm}$; maximum body width, $9.1 \mathrm{~mm}$; distance from male gonopore to anterior tip, $8.0 \mathrm{~mm}$; width of oral sucker, $2.0 \mathrm{~mm}$; width of caudal sucker, $3.5 \mathrm{~mm}$; ratio of oral sucker to caudal sucker, 0.57 ; ratio of caudal sucker to maximum body width, 0.385 .

The head is somewhat rounded and broadly confluent with the body apart from a barely perceptible narrowing in the neck region (segments VI-VII). The eyes are contiguous in segment III, and located in the posterior part of a clear, unpigmented area which extends anteriorly to the apex of the head. The oral sucker occupies the ventral portion of the head. It is broadly triangular and somewhat cupped (at least as fixed in this specimen). Its posterior rim is thick and formed by annulus IVa3. This rim is unpigmented, like the rest of the oral sucker, and is clearly demarcated ventrally from annulus $\mathrm{V}(\mathrm{a} 1+\mathrm{a} 2)$ which by contrast is well pigmented. The small mouth pore is evident only in certain lighting and lies very near the apex of the sucker.

The caudal sucker is a substantial muscular organ attached essentially at right angles to the body. It is a solid, more or less circular structure roughly one-third the maximum width of the body. The dorsal surface of the caudal sucker bears about seven pigmented stripes, and a concentric inner row of inconspicuous tubercles. Its ventral surface has a shallow depression, the centre of which displays six or seven pairs of radial muscle bands, along with some concentric muscles.

Pigment patterns. The dorsal surface of this individual is heavily pigmented, whereas the venter is much less so (Fig. 3B). The base colouration of the dorsum is a cryptic light brown comprised of numerous very fine chromatophores distributed uniformly in the tegument. Against this background, the following areas are stark in their lack of tegumentary pigment: the apex of the head, including the area bearing, and anterior to, the eyes, and the ventral surfaces of the oral and caudal suckers. Furthermore, the a3 and a1 annuli of adjacent segments lack tegumentary pigment at the margins. The unpigmented metameric margin is best seen in life (see Fig. 6A, ma), especially when the animal is extending. 
Placobdellid head pattern. In the head and neck regions there is a medial ornate cream-colored pattern of varying widths, vaguely reminiscent of the head pattern of a cobra (Fig. 3A, pp). This 'placobdellid' head pattern is phylogenetically conservative and occurs in other species of Placobdella in the Albemarle region, including $P$. parasitica. In the current individual the pattern begins in segment IV immediately behind the eyes. It extends as far posteriorly as annulus VIIa1, inclusively.

Metameric marginal pattern. The margins of this archetype specimen display conspicuous light areas repeated at segmental intervals along the entire length of the body (Fig. 3A, ma). In detail, the light area is comprised of two contiguous annuli (a3, a1), separated by a darkly pigment annulus (a2). Each light annulus bears aggregates of large cream-colored chromatophores called here 'colossal cells' for convenience. Closer scrutiny reveals these aggregates are actually located within a larger unpigmented area which accentuate the presence of these patches in life. These colossal cells serve as useful segmental landmarks in that they are located invariably on a1 and a3 annuli of each segment, virtually never on the a 2 annulus, the middle annulus of each respective segment. The contiguous annuli a3 and a1 constitute one metameric patch but actually it is derived from two adjacent segments. These marginal light patches extend anteriorly as far as segment $\mathrm{V}$, and posteriorly as far as segment XXIV.

Mid-dorsal stripe. An interrupted narrow band or stripe is darker brown than the background. It is most conspicuous in the posterior half of the body at about segment XVII (XV1a3-XVIIIa1) and segment XX (XIXa3-XXIIa2). The stripe is interrupted by mid-dorsal light areas also most conspicuously in the posterior half of the body, especially at XVIIIa2-XIXa2 and XXIIa3-XXIVa3 in the pre-anal region. There is also an ill-defined light area in the genital segments XII-XIII, preceded by an ill-defined brown stripe in roughly segments VIII-XI.

Annulation. Annulation and segmentation of this specimen are interpreted as follows: segments I and II consist of 1 annulus each; segment III consists of 2 annuli, the eyes on fused annulus III (a1+a2), followed by annulus IIIa3; segment IV consists of two annuli IV(a1+a2) and IVa3. The oral sucker is comprised of segments I-IV, and unpigmented ventrally. Segment V has 3 annuli dorsally whereas the first two annuli fuse ventrally as $\mathrm{V}(\mathrm{a} 1+\mathrm{a} 2)$. This is the first pigmented annulus ventrally, and starkly borders the unpigmented posterior rim of the sucker at IVa3. Segments VI-XXIV are each comprised of 3 annuli, dorsally and ventrally. Segment XXIV has 3 annuli, and is the last segment with a tubercle in intermediate position in a longitudinal series. Segment XXV has 2 incipiently divided annuli; segment XXVI is 1 annulus; and XXVII is 1 subdivided annulus, bearing the anus in the furrow. Of possible taxonomic significance, this specimen therefore has 19 complete (3-annulate) segments VI-XXIV, inclusively.

Dorsal tubercles. This archetype specimen has seven linear rows of tubercles arranged longitudinally along most of the dorsum (Fig. 3A). In spite of numerous small extraneous tubercles in this specimen, the overall effect does not give a particularly rough appearance. The tubercles are located in the following positions: medial (tm), paramedial (tp), intermediate (ti) and paramarginal (ta) (see Fig. 12). It must be noted that in this specimen additional tubercles of varying sizes, while never large, occur extraneously on virtually every annulus. Nonetheless, these do not obscure the predominant multilinear pattern of seven rows. Some of the tubercles are pigmented, either randomly or part of a pattern.

By far the most prominent is the intermediate row of tubercles. These relatively large structures are positioned invariably on the a2 annulus from segment VII to XXIV, inclusively. At least in this archetype specimen segment VI is peculiar in that the intermediate tubercle is lacking on the left side, and diminutive on the right. Another peculiar feature of the head is an aggregation of 'colossal cells' in the serially homologous intermediate positions of segments V and IV. Those of segment IV are particularly prominent and look like pseudo-eyes from a distance (see Fig. 10A, B, lp). They are located on either side of, and on second annulus behind, the eyes.

The next most prominent linear row of tubercles is that in medial or mid-dorsal position. Like the intermediates they are positioned only on the a2 annulus from segment VI to XXIV, inclusively. Compared to the intermediate row the mid-dorsal tubercles are relatively smaller, more variable in size and partially obscured by the interrupted pigmentation of the mid-dorsal stripe. The paramedial row of tubercles differs from the intermediates and median in being located invariably on the a3 annulus of each segment.

The paramarginal row of tubercles differ from the others in being small and numerous, as well as located almost randomly in the paramarginal position on virtually every annulus from about segment VIII to about XXV. However, those on the a 2 annulus are perceptibly larger than those on the other annuli. Furthermore, uniform fine tubercles aggregate toward the very margins of each a2 annulus, an arrangement which hints of some degree of sensory selforientation. 
Peduncle. In this specimen, the three caudal segments XXV-XXVII constitute a distinct peduncular or pre-anal region defined by three respective pairs of prominent tubercles on either side of the midline. The midline itself is relatively smooth, almost furrow-like, terminating at about the anus.

From a dorsal perspective the circumference or outer rim of the caudal sucker visually intersects the margin of the body at XXIV/XXV, the precise point separating the pre-caudal segments from the three peduncular segments. From this point the margins of these three caudal segments adopt a straight-line trajectory terminating where the peduncle attaches to the sucker. Segment XXV has 2 annuli, XXV (a1+a2) incipiently divided from XXVa3; the former enlarged annulus bears a prominent paramedial tubercle. Segment XXVI has 1 annulus which bears a tubercle of similar size and position as that on segment XXV. Segment XXVII, is unique in that it is divided by the anus. The anterior portion of this annulus bears a large tubercle of similar size and relative position as the two preceding segments.

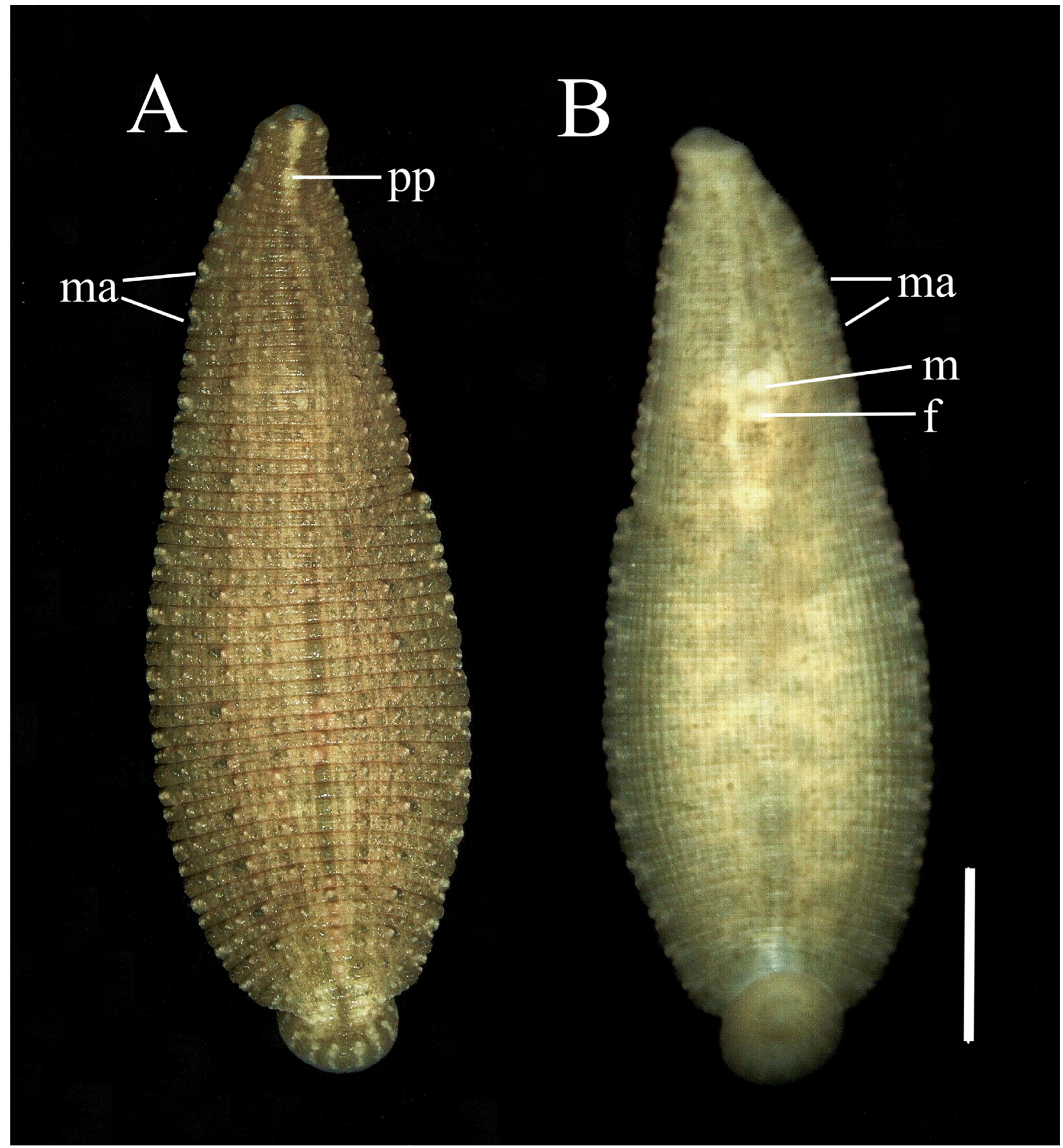

FIGURE 3. Archetypal specimen of the Albemarle turtle leech on which the external description of this species is based. Collected at edge of swamp, Stephens Ridge, Gum Neck, Tyrrell County, NC (PM-14d). A, dorsal view. B, ventral view of same specimen. Scale bar: $5.0 \mathrm{~mm}$. 
Venter (Fig. 3B). The venter of the archetype is smooth and characterized by fine longitudinal striations, about 20 on each side, being more prominent toward the margins. The ventral tegument is very lightly pigmented with olive-coloured chromatophores. In the pre-genital and genital segments VII to XIII these pigment cells are somewhat organized into a vague pair of faint splotchy bands, one on each side of the midline. In the post-genital region these chromatophores are increasingly infrequent and randomly distributed toward the posterior. The only other pigment pattern visible from the venter is the metameric marginal pattern more clearly seen from the dorsal side.

Both gonopores are visible at the ventral mid-line (Fig. 3B, m, f). The male gonopore is surrounded by concentric tissue, resulting in a squatty cone well raised from the ventral body wall (in the archetypal specimen at least). It is located at XIa3/XIIa1 where it serves as the most reliable external reference point for determining segmentation and annulation. The less conspicuous female gonopore is flush with the ventral body wall and located at XIIa2/a3, in a furrow two annuli behind the male. Interestingly, in this specimen both the male and, to a lesser extent, the female gonopores and adjacent tissue fluoresce intensely under ultraviolet light.

So as not to destroy external features the archetype specimen was not dissected but the tegument of the venter is so lightly pigmented and translucent that it reveals the precise locations of key internal landmarks, including the ventral nerve cord, proboscis, salivary glands, crop and some reproductive structures. For example, in this specimen the ovisacs are relatively short, extending posteriorly only as far as XIV-XV. This indicates that this specimen is not fully gravid. The crop is voluminous and blood-filled in this specimen, and its outline is just visible through the ventral body wall. It conforms closely to the description in the section on variability.

\section{Internal features}

The internal anatomy of the Albemarle turtle leech is based on dissection of a single carefully relaxed reference specimen from the same series as that on which the external features are described above. This specimen (PM-1b) is gravid, so supplementary observations of especially the reproductive systems are made on a non-gravid individual (PM-4) of similar size from the same series. The crops of both dissected archetypal specimens are replete with blood.

\section{Foregut}

Proboscis complex. The proboscis of this individual (PM-1b) is remarkably long and whip-like (Fig. 4, p). It is a gently tapered structure with its base located at, or slightly anterior to, the level of ganglion XI. In this specimen the proboscis is effectively too long for the space available, an impression corroborated by a crook or J-bend of the proximal end of the proboscis at X/XI. This flexure also includes the anterior portion of the oesophagus and together they accommodate at least $10 \%$ additional length of the proboscis complex when everted through the mouth pore. Fully extended in this relaxed specimen the distance from the base of the proboscis to its tip is in excess of $10 \mathrm{~mm}$.

The anterior end of the proboscis tapers to a notably narrow tip, definitely not broad nor blunt. In this specimen the tip lies anterior to the brain (circum-proboscis commissure) through which the proboscis penetrates (Fig. 4, b), and accordingly lies in situ very close to the mouth pore at the anterior rim of the oral sucker. The entire proboscis is muscular and encased within a thin sheath readily discernible in dissection as far posteriorly as its base. At the level of g. VII on each side a conspicuous tendon-like band attaches from the lateral margins of the sheath and extends anteriorly and laterally to terminate in the body wall anterior to the brain. These paired tendons presumably support protractor muscles.

The base of the proboscis lies toward the dorsal mid-line at the level of, or slightly anterior to, g. XI. It is a complex structure which receives on each side a sizeable bundle of salivary ductules. Slightly medial to, and almost contiguous with, each salivary bundle is a conspicuous tendon-like band of presumptive retractor muscles which proceed anteriorly to terminate on either side at the dorsal body wall. Interestingly, as the oesophagus emerges from the middle of the proboscis base, it bends tightly around the base of the left salivary ductule/ left retractor muscle before descending to the ventral floor, a rare instance of departure from bilateral symmetry in the foregut.

At the posterior end of the base of the proboscis emerges a thin-walled, non-muscular oesophagus which continues as a narrow tube anteriorly and ventrally to anchor onto the ventral floor at X/XI (Fig. 4, oe). From there the oesophagus proceeds posteriorly along the ventral floor passing just above the male and female structures, and terminating about XIII to join the thin-walled crop which is filled with blood in this specimen. No blood is found in the oesophagus itself. In the region between XI and XII the oesophagus in this specimen convolutes somewhat. Along the length of the oesophagus are a few, isolated very large cells of unknown function. 
Just posterior to where the oesophagus anchors to the ventral floor at X/XI on either side emerges a sac-like mycetome (Fig. 4, my). In this specimen this structure is poorly defined but proceeds laterally along the ventral floor before turning posteriorly and laterally to terminate at about the level of g. XI.

Salivary glands. The salivary complex is comprised of two conspicuous pairs of compact salivary 'glands' (Fig. 4, sa, sp). The anterior gland is positioned medial to the much larger posterior gland. In this specimen (PM-1b) the anterior gland extends from posterior to ganglion VIII to IX/X, with a long, thin bundle of ductules which extends posteriorly to connect to a similar bundle emanating from the posterior salivary gland. The more conspicuous posterior salivary gland is elongated lengthwise and positioned from posterior to IX to about XI/XII. The posterior gland indents at about X, from which region a relatively large bundle of ductules extend medially and posteriorly. This bundle is joined at about one-third of its proximal length (i.e., closer to the proboscis than to the posterior gland) by the much thinner bundle from the anterior gland to form a substantial common salivary bundle which enters the base of the proboscis. Some salivary cells from the posterior gland extend nearly to the point of juncture of the anterior and posterior bundles, but there are relatively few salivary cells along the common bundle. These bundles consist of ductules from individual salivary cells rather than a hollow duct or lumen for conveying secretions as in vertebrate glands. In this preserved specimen the salivary cells are basically achromatic from whitish to varying shades of grey. Some of the cell bodies in both the anterior and posterior glands are large, on the order of $100 \mu \mathrm{m}$ or larger.

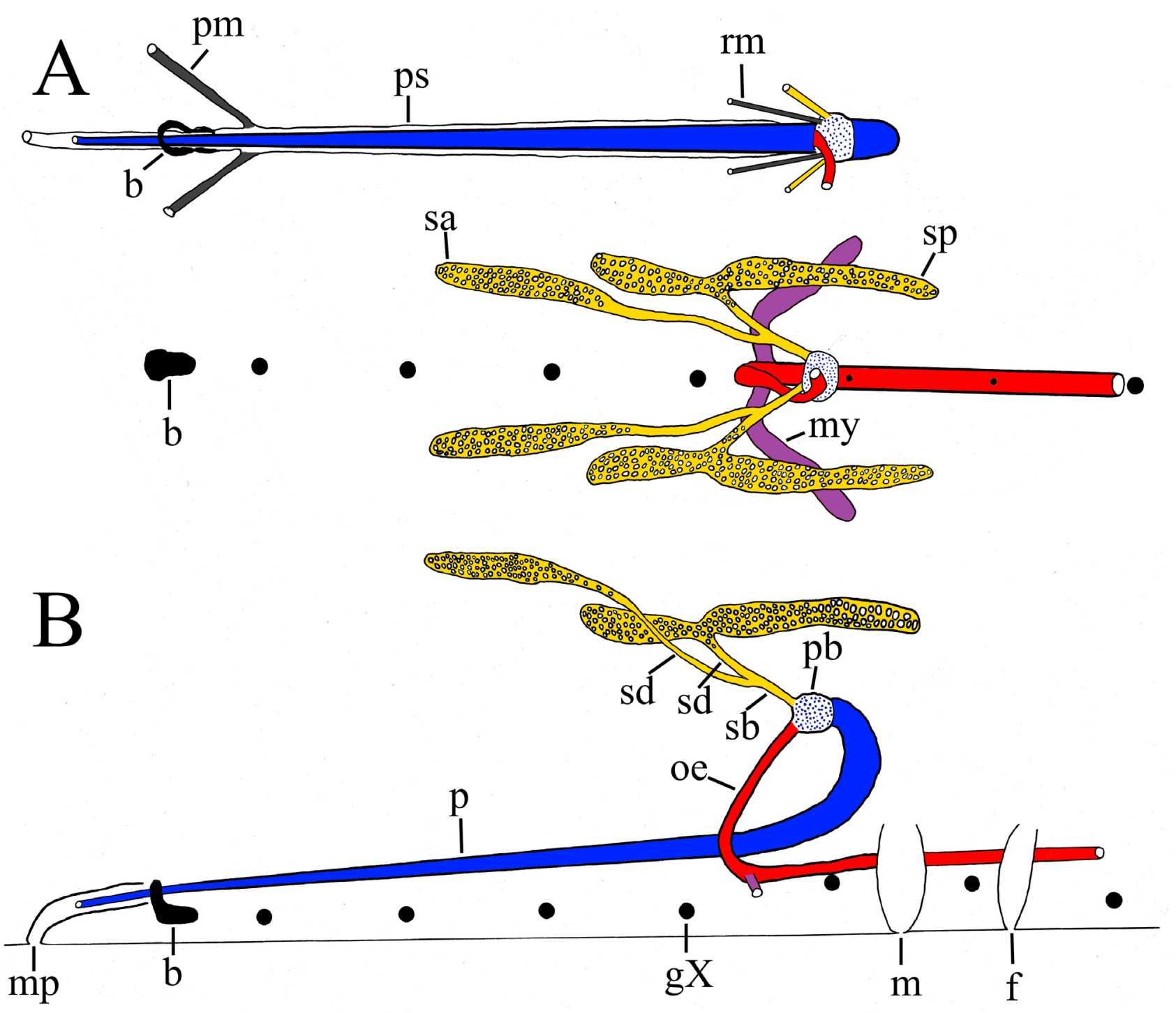

FIGURE 4. Scheme of the proboscis complex of the Albemarle turtle leech, based on dissection of specimen PM-1b from Tyrrell County, NC. A, dorsal view, with proboscis inset separately for clarity. B, lateral view. The long tapering proboscis (blue), with a proximal crook and termination of its tip beyond the brain, is specific for this species. Proboscis is approximately $10 \mathrm{~mm}$ long. 
Crop and intestine. In this engorged individual the blood-filled crop was not dissected in detail. However, the mid-gut closely resembles that described in the section on variability. The hind-gut consists of the intestine with four pairs of unbranched caeca (see Fig. 6B, ic), and the rectum which opens at the anus (see Fig. 14B, r).

\section{Reproductive structures}

Male system. In this specimen (PM-1b) the male system on each side is comprised, from anterior to posterior, of an atrium, atrial horn, ejaculatory duct (distinctly muscular), seminal vesicle (non-muscular, thin-walled), vas deferens and testisacs (Fig. 5). The ejaculatory duct and seminal vesicle lie essentially between ganglia XI and XII and between ganglia XII and XIII, respectively. Rather than being straight tubes the ejaculatory duct and seminal vesicle each convolute several times in their respective segments.

The paired ducts of the male system meet anteriorly to terminate as contiguous left and right atria located in this specimen posterior to ganglion XI. There is essentially no unpaired median structure (i.e., no penis). At the point of divergence the two atria are tightly constrained dorsally by the ventral nerve cord, dorsal to which lies the oesophagus.

The atrium is a conspicuous structure of mostly uniform diameter. From the ventral midline each ascends dorsally and in so doing diverges slightly from its partner but does not splay laterally to any significant degree. However, the atrium does have a slight anterior projection. The upper tip of the atrium gives rise anteriorly to a short transitional horn which increases in diameter somewhat to form the ejaculatory duct (Fig. 5, ah, ed). This short atrial horn is translucent revealing little musculature. In contrast the wall of the ejaculatory duct, throughout its length, is opaque with a conspicuous sheen reminiscent of circular muscles.

The ejaculatory duct descends abruptly from the atrial horn more or less vertically onto the ventral body wall. From there it ascends anteriorly, looping once or twice, not far beyond the level of g. XI. From there it reverses and extends posteriorly as a somewhat convoluted tube which eventually descends again to the ventral floor about at the level of g. XII.

From the ventral floor a short ascending portion of the still muscular ejaculatory duct abruptly joins the seminal vesicle of somewhat wider, but less uniform, diameter. The translucent seminal vesicle is non-muscular and thinwalled, through which can be seen loosely aggregated flocculent material. The seminal vesicle extends posteriorly in a convoluted fashion and ends abruptly just behind the level of $\mathrm{g}$. XIII, to join the vas deferens. The left seminal vesicle loops two to three times and is mostly confined to the region between $\mathrm{g}$. XII and g. XIII, anterior to the first pair of crop caeca. The vas deferens is exceedingly difficult to trace further. In this specimen the testisacs were not determined but in other specimens there are six pairs of testisacs located between the crop caeca just behind the ganglia of segments XIII-XVIII, respectively.

Female system. The female system of this gravid specimen (PM-1b) is comprised of a pair of bifurcated ovisacs (Fig. 5, oc). These are essentially simple elongated tubes with little convoluting so characteristic of the male system. Like the male, the female system has no unpaired median structures (i.e., no vagina). There is no formed structure comparable to the male atria, nor any muscular portion comparable to the ejaculatory duct. The paired ovisacs join at the ventral midline at XIIa2/a3.

On either side the common ovisac bifurcates into a short median arm and a much longer posterior arm. These elements are somewhat plastic depending on the state of reproduction, being much more developed in this gravid specimen which was collected in mid-May at the peak of reproductive season. The common ovisac extends posteriorly as far as the level of $\mathrm{g}$. XIV where it bifurcates. This common ovisac is wide, thin-walled and quite translucent revealing conspicuous ova of irregular sizes, giving the appearance of cooked tapioca. These ova are visible as far posteriorly as the above mentioned bifurcation. At the bifurcation a short medial sac extends anteriorly (in this specimen), to terminate dorsally at the level of g. XIII. At the tip of this medial sac is a shiny ligament-like extension. This relatively inconspicuous medial arm is narrow in diameter and contains no apparent ova in spite of the translucent nature of its wall.

Returning to the bifurcation at XIV, the main ovisac extends posteriorly into the ventral sinus as far as about ganglion XVIII or beyond. Interestingly, this elongated sac is not attached at its distal end and can be gently teased entirely out of the sinus. This posterior arm is also translucent and thin-walled, through which can be seen a loose assortment of irregular string-like tissue. 


\section{Variation of reproductive structures}

The reproductive system of the reference specimen (PM-1b) serves as a baseline for meaningful comparisons with other dissected specimens as indicated (Fig. 5). However, no attempt was made to follow development of the reproductive systems in this study.

Male system. The position of the atria in relation to the sex ganglion XI varies among specimens dissected in this study. In some individuals the atria are tight against $\mathrm{g}$. XI whereas in others the atria are well posterior to $\mathrm{g}$. XI. Interestingly, the difference between these two relative positions is that the distance between $\mathrm{g}$. XI and g. XII is significantly fore-shortened in the former specimens.

Three invariant, taxonomically significant landmarks of the ejaculatory duct, found in all dissected specimens, are: (1) its abrupt descent from the atrial horn onto the ventral floor in segment XI; (2) its anterior extension not much beyond the level of g. XI (albeit looping once or twice); and (3) its descent to the ventral floor about at the level of g. XII. On its final posterior ascent the ejaculatory duct abruptly joins the non-muscular seminal vesicle. In nearly all dissected specimens, the seminal vesicle is well convoluted and confined between g. XII and g. XIII. However, the seminal vesicle on the right side of the reference specimen (PM-1b) is atypical in not being convoluted in this region; instead it extends posteriorly as a simple loop to nearly the level of $\mathrm{g}$. XIV before turning anteriorly to terminate just behind $\mathrm{g}$. XIII.

Female system. The female system is remarkable plastic in this species and therefore taxonomically unreliable. In the various dissections only the anchoring of the median arm of the ovisac dorsally in segment XIII appears to be a fixed landmark of possible significance (Fig. 5B, pa).
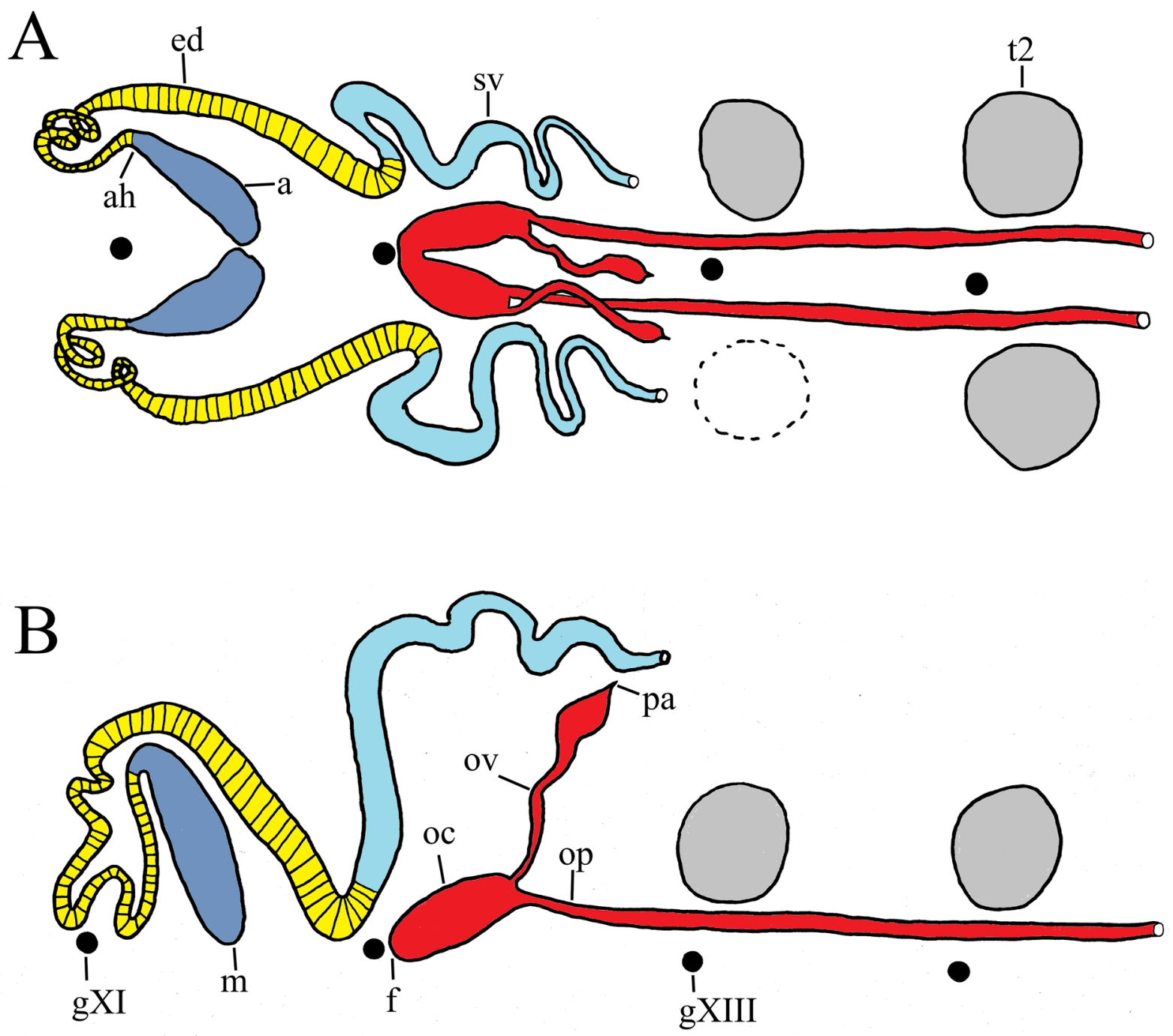

FIGURE 5. Scheme of the reproductive systems of the Albemarle turtle leech, based on dissection of specimen PM-12 from Pasquotank County, NC. A, dorsal view. B, lateral view. Distance between segmental ganglia is approximately $2.0 \mathrm{~mm}$. 
The reference specimen (PM-1b) described above was fully gravid. For comparison, a non-gravid individual (PM-4) from the same series and of comparable size $(39 \mathrm{~mm})$ was collected in mid-October, well out of the reproductive season. The female features of this non-gravid individual differ markedly. On the left side the female system of this non-gravid specimen is comprised of the same three elements, i.e., common ovisac with larger posterior and shorter medial arms beyond the bifurcation. However, the several components are noticeably shorter than that in the gravid individual, whereby the bifurcation is located at about the level of g. XIII (not XIV). The posterior arm extends only to about g. XIV (not XVIII). The smaller medial arm extends posteriorly (not anteriorly) but does anchor with a ligament at the same position, i.e., dorsally at about g. XIII. The ovisac of the right side is tightly coiled and lies mostly between g. XII and g. XIII. The bifurcation is just behind g. XII, and the posterior arm extends only just beyond g. XIII.

The location of the bifurcation of the ovisac varies in the different dissections from behind $\mathrm{g}$. XII (PM-4, right side), XII/XIII (PM-12), g. XIII (PM-4, left side, PM-21a) to g. XIV(PM-1b). Because the median arm is fixed dorsally just anterior to $\mathrm{g}$. XIII, the median arm faces either anteriorly or posteriorly. The full posterior extension of the ovisac varies from g. XIII (PM-4, right side), g. XIV (PM-4, left side), g. XV (PM-12), g. XVI (PM-21a) to beyond g. XVIII (PM-1b). In one individual the ovisac bifurcates twice (PM-4, right side).

\section{Variability, development and taxonomic analysis}

In this section, key taxonomic characters are appraised with regard to their overall significance toward the formal diagnosis of the Albemarle turtle leech. Emphasis is on identifying those characters which are found in all individuals of this species, but are not found in outgroup species including $P$. parasitica. The central methodology focuses on exposing taxonomically unsound characters, i.e., identifying and downgrading for diagnostic purposes those variable characters which occur in some but not all individuals of this species.

Biological observations throughout this study reveal that variability also encompasses the degree of change which this species undergoes during growth and development. Accordingly, development of selected characters is also explored in this section in order to extend their usefulness in the taxonomic diagnosis of this species to ever earlier stages.

\section{External features}

A homogenous sample of 15 adults of similar size and maturity from diverse localities in the Albemarle region are examined for variability (Fig. 1B) (see Appendix). Each was collected during the breeding season, primarily AprilMay (mean length, $37.5 \mathrm{~mm}$, range 29.5-45.0 mm, N=15). A total of 96 external characters are identified, against which each of the 15 individuals is critically assessed. Using the foregoing description of the archetype specimen (PM-14d) as a baseline, similarities and differences of these external characters are examined in detail.

In order to minimize subjectivity, maximum use is made of photography (see Methods). Images are taken variously with LED, ultraviolet and/or incandescent lighting, sometimes with remarkably different results (Fig. 6). For occasional points of clarification certain specimens are re-examined microscopically, as required.

By way of summary, certain external features are highly conserved. Such invariant characters include location of the respective gonopores; apical location of the mouth pore; confluent eyes located on segment III; the oral sucker formed by segments I-IV and rimmed ventrally by segment V; segments VI-XXIV each tri-annulate (i.e., 19 complete segments); presence of placobdellid head pattern and marginal metameric pattern; and absence of a white nuchal ring. These specified invariant features can be considered characteristic of the Albemarle turtle leech. However, these features also occur in outgroup species including P. parasitica (PP-4a) and therefore they are not diagnostic for the Albemarle species for the purposes of this study.

Pigment patterns. As discussed in detail below, the placobdellid head pattern and metameric marginal pattern are indeed characteristic (but not diagnostic) of the Albemarle turtle leech in that they occur in virtually all specimens of this species.

Placobdellid head pattern. The placobdellid head pattern as described in the reference specimen is one of the most resilient external features of the Albemarle turtle leech (see Figs. 3A, 6, 7, 10, pp). It is found in all specimens in this study, even those which are otherwise very faded. There is notable variation in expression of this pattern in detail, but in its most basic form it consists of three consecutive cream-colored patches of varying widths centred on IVa2/a3 (invariably originating immediately behind the eyes), Va3 and VIa3, respectively. These three patches are more or less contiguous, typically linked by a narrow waist at the midline. 
In addition, many specimens have what appears to be a fourth patch in the sequence centred at VIIa3+VIIIa1. However, this entity is not really a constituent part of the very stable placobdellid head pattern in that it is comprised of different and less durable kind of pigmentation. Thus, this fourth patch is often faded or even absent in different individuals. Revealingly, under ultraviolet light this fourth patch does not fluoresce, as do the patches of the true placobdellid pattern.

One previously overlooked feature of the head of the Albemarle turtle leech is a pair of conspicuous light-coloured lateral patches or round spots located on either side of segment IVa1+a2, behind and lateral to the true eyes of this species. This relatively prominent feature is found in virtually all examined specimens, including the reference specimen (see Figs. 3A, 10A, B, lp). Interestingly, its relatively large size and constant location on the head is vaguely reminiscent of pseudo-eyespots commonly found in caterpillars and butterflies. It is serially homologous with a similar but much less conspicuous spot on annulus Va2.

Metameric marginal pattern. The metameric marginal pattern is present in all specimens examined (see Figs. $3 \mathrm{~A}, 7 \mathrm{~A}, 10 \mathrm{~A}, 15 \mathrm{~A}, \mathrm{ma})$. All specimens resemble the archetype specimen in that each marginal patch is comprised of a conspicuous aggregation of large cream-colored 'colossal cells' confined to the contiguous annuli a3 and a1, and absent on the middle or a 2 annulus (see Fig. 10A, C, cl). In some specimens the 'colossal cells' are arranged in a distinct horseshoe configuration with the open end toward the margin.

In juvenile specimens the 'colossal cells' are embedded in, and visually overwhelmed by, a spacious unpigmented or clear area, especially evident in life (Fig. 6A, B). In older, highly pigmented specimens this clear area is essentially crowded out, leaving the 'colossal cells' as virtually the only metameric markers along the margins.

Development of pigment patterns. Prior to first feeding perceptible aggregations of presumptive 'colossal cells' are already evident in cardinal locations in the transparent embryo. These large cells are easily discernible in embryos at least as early as $7.8 \mathrm{~mm}$ (see Figs. 13B, 14C, 15C, cl). A significant number are positioned at the dorsal midline of the head in segments IV to VI, respectively (future placobdellid head pattern). Others are positioned segmentally at the lateral margins along the length of the body (future metameric marginal pattern).

The first blood meal triggers expression of a perceptibly darker background comprised of uniformly distributed fine brownish chromatophores. Counterintuitively, it is not the presence of the brown pigment which defines the abovementioned pigment patterns. Rather, it is the absence of pigment which by silhouette sharply highlights both the head and marginal patterns so characteristic of this species. Thus, the placobdellid head pattern is revealed as contiguous unpigmented areas along the head and neck midline in segments IV-VI. Similarly, the metameric marginal pattern is seen as unpigmented areas in the margins of the a1 and a 2 annuli along the length of the body. Parenthetically, the area in front of the eyes is also unpigmented (see Fig. 10A, ua). Of developmental and taxonomic significance the head, marginal and pre-ocular patterns correlate with the distribution of these 'colossal cells' which persist as cream-coloured cells into the adult.

A developmental generalisation from the foregoing is that the major pigment patterns characteristic of the Albemarle turtle leech may be determined ultimately by a factor(s) which leads to the strategic positioning of these presumptive 'colossal cells' in the early embryo.

Furthermore, the presence of strategically localised 'colossal cells' and absence of surrounding pigment suggest an underlying developmental process. In other words it may be possible that the 'colossal cell' actually suppresses pigment formation in its vicinity. Such conjectural pigment suppression appears to be unknown in invertebrates, but pigment suppressing agents have been reported in vertebrates, including fish (Cooper 2017; Solano et al. 2006).

Absence of nuchal ring. Of considerable taxonomic significance by its absence, none of the specimens of the Albemarle turtle leech, not even juveniles, displays a white nuchal ring, the lack of which also characterises the outgroup species P. parasitica (PP-4a). However, in the Albemarle region lives more than one sympatric species which clearly have such a ring. Furthermore, the nuchal rings of these as yet unidentified species are associated with the aforementioned 'colossal cells' and are reminiscent of that recently illustrated by Moser et al. $(2020$, fig. 1) for Placobdella michiganensis (Sawyer, 1972).

Mid-dorsal stripe. The presence of a mid-dorsal brown stripe, especially whether it is interrupted or continuous, is taxonomically unsound for diagnosing the Albemarle turtle leech. This is due not only to the variable nature of this character and changes during maturation, but also because its apparent presence is greatly affected by preservation and lighting (Fig. 6, s).

In this species an interrupted stripe is most clearly displayed in younger individuals in life (Fig. 6A) with general diminution of the interruptions during maturation. In a series of preserved adults a continuous stripe occurred 
in $38 \%$ of individuals, an interrupted stripe in $56 \%$ of individuals (nearly equally split between definite and partial interruptions) and no or barely detectable stripe in $6 \%$ of individuals $(\mathrm{N}=16)$ (Fig. 7). Some heavily pigmented individuals display a continuous median stripe flanked anteriorly by two paramedian stripes (Fig. 10A, B, pd). Rarely, the two paramedian stripes extend posteriorly along most of the length of the dorsum resulting in three apparent dorsal stripes.

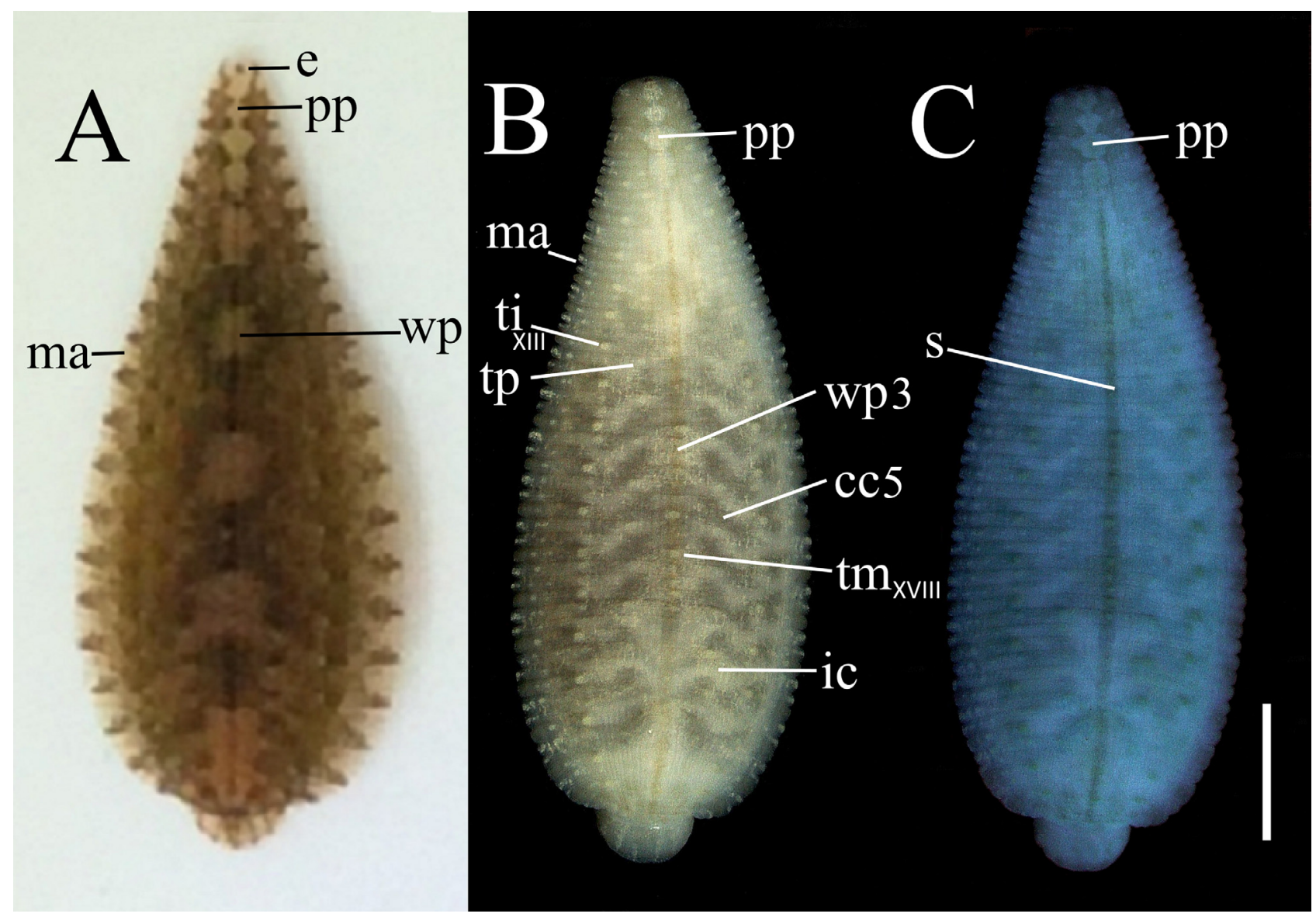

FIGURE 6. Taxonomic features of the Albemarle turtle leech can vary considerably under different conditions of lighting and preservation. Shown is a recently fed, late juvenile specimen (PM-20) from Virginia Beach, VA, photographed as follows. A, in life, under natural light. B, same individual relaxed and preserved in $5 \%$ formalin, under LED light. C, same preserved individual, under ultraviolet light. Scale bar: $2.0 \mathrm{~mm}$.

The dorsal stripe arises metamerically early in development, apparently only after the first blood meal. Concentrations of fine brown chromatophores are deposited at segmental intervals along the dorsal midline along most of the length of the body. Based on limited observations pigment deposition arises independently in each segment, to coalesce longitudinally during development to form a continuous stripe. With growth the stripe becomes more prominent, but typically becomes interrupted by white shields discussed below.

Cartouche-like white 'shields'. Special mention should be made of five cartouche-like white shields or patches positioned at fixed intervals along the dorsal mid-line. These are especially evident in younger, sub-adult individuals (Fig. 6A, wp). These shields are nearly opaque and obliterate the otherwise continuous underlying stripe to constitute apparent 'interruptions'. Such an interrupted stripe is typical of post-fed juveniles and sub-adults of this species. However, with increasing age and concomitant pigmentation these white shields and underlying stripe are subject to considerable obfuscation (Fig.7). 


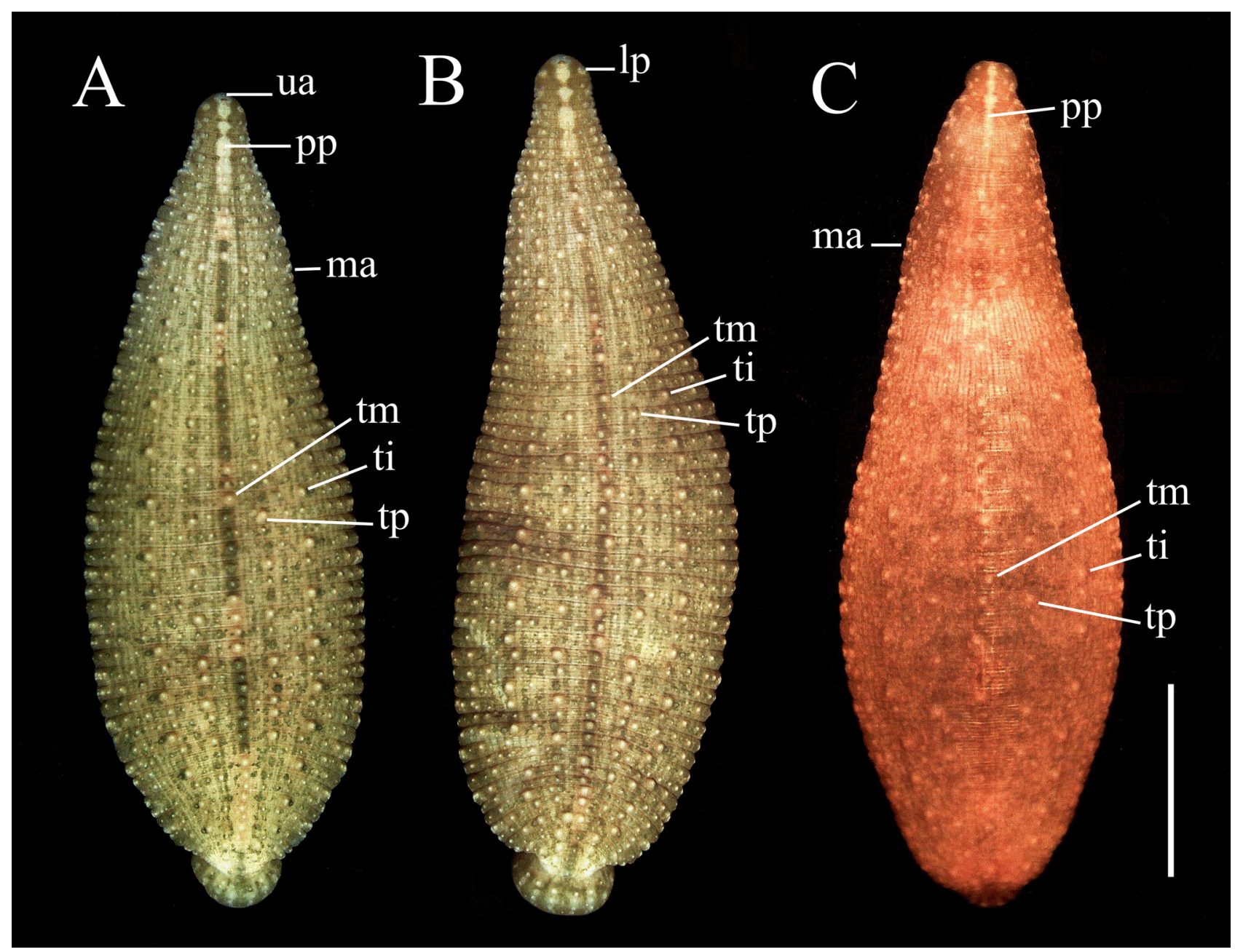

FIGURE 7. Variation of the dorsal stripe and tubercles in the Albemarle turtle leech. A, interrupted dorsal stripe (PM-15a). B, continuous dorsal stripe (PM-15c). C, no discernible dorsal stripe (PM-12). The primary tubercles, ti and tm on the a2 annulus, and tp on the a3 annulus, together with their bilateral counterparts, constitute a flattened letter ' $\mathrm{W}$ '. This configuration is specific for the Albemarle turtle leech. Furthermore, in this species the intermediate tubercles (ti) are invariably the most prominent. Dorsal views. A, B, LED light; C, incandescent light. Scale bar: $10 \mathrm{~mm}$.

Unlike the marginal and head pigment patterns discussed above, these dorsal shields are not strictly metameric in that they typically overlap two or more adjacent segments. Typically the five shields are centred mid-dorsally at IX-X (\#1, pre-genital), XII-XIII (\#2, genital), XV-XVI (\#3, mid-crop), XVIII-XIX (\#4, pre-intestine) and XXIIIXXIV (\#5, anal), respectively. Moreover, the limits of a given shield may vary by one or two annuli. For example, in the archetype specimen the \#4 shield lies precisely from XVIIIa2 to XIXa2, and \#5 shield from XXIIa3 to XXIVa3, inclusively (Fig. 3A). In some, especially younger, individuals the \#1 shield covers segments VIII-XI, inclusively, and \#5 shield extends well into the peduncle virtually to the anus (Fig. 6A, wp).

These dorsal shields arise early in development, at least by $4.8 \mathrm{~mm}$, as a layer of whitish cells (Fig. 8B, wp). Under transmitted light these cellular aggregates are clearly discernible in their respective fixed positions in the transparent early embryo, as well as translucent juveniles (see Figs. 8A, 14B, C, wp). Based on limited observations these shields apparently arise before the first blood meal, and therefore before appearance of the brown dorsal stripe.

The opacity and fixed positions of the shields may suggest a functional role in protecting underlying vital tissue, e.g., ovisacs or mycetomes, from radiation or similar damage. By way of caution this explanation, while seemingly reasonable, remains speculative and circumstantial. 


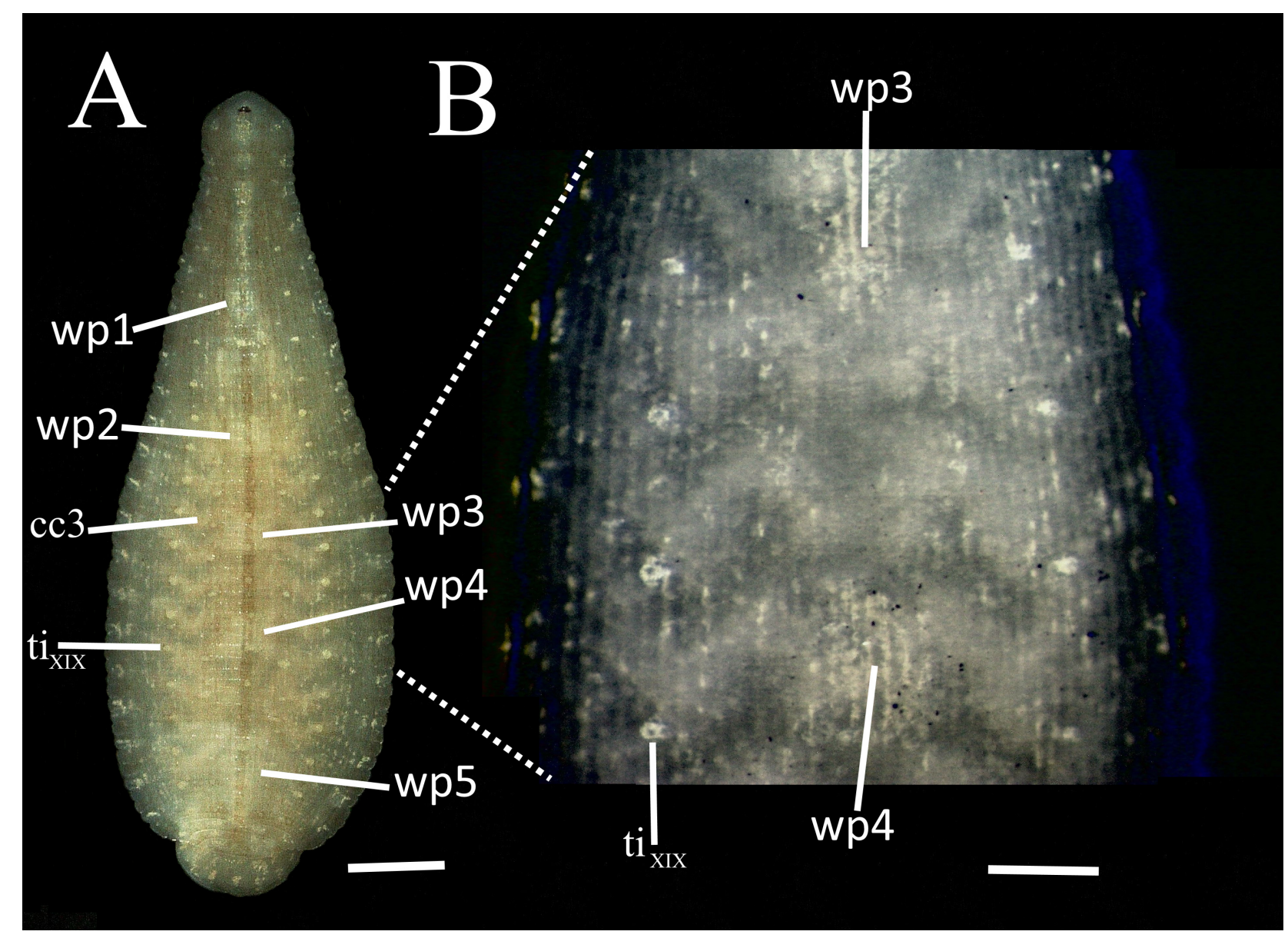

FIGURE 8. Cartouche-like rectangular shields are the basis of the interrupted stripe in the Albemarle turtle leech (see also Fig. $6 \mathrm{~A}, \mathrm{~B})$. A, in this preserved, post-fed juvenile (PM-17f, $7.8 \mathrm{~mm}$ ) the dorsal stripe is continuous along most of the dorsal midline, but is obfuscated at intervals by the opacity of the respective shields. B, the cellular nature of these shields is shown in a slightly earlier stage of development. In this specimen (PM-24a, $7.8 \mathrm{~mm}$ ) consecutive shields 3 and 4 are comprised of aggregations of white cells localised mid-dorsally at segments XV/XVI (wp3) and XVIII/XIX (wp4), respectively. A, reflected LED light; B, transmitted LED light. Scale bars: A, $1.0 \mathrm{~mm}$; B, $0.3 \mathrm{~mm}$.

Of taxonomic interest, the hatchling of the outgroup species $P$. parasitica more closely resemble the young of the Albemarle leech than the adult of $P$. parasitica. The hatchling of $P$. parasitica also has five prominent light shields (PP-4b, $6 \mathrm{~mm}$ ), but these are not evident in the adult. In some juvenile $P$. parasitica these shields, or their associated cellular components, have expanded irregularly into wide cream-coloured patches which may become broadly confluent but still centred at the same ordinal locations (PP-3, $12 \mathrm{~mm}$ ). In adult P. parasitica this underlying pattern may become obfuscated or lost entirely, especially in mid-body segments XI-XXII (PP-2, PP4a).

Placobdellid eye. The true eyes are invariably close together and develop remarkably early (at least by 4.3 $\mathrm{mm}$ ), long before any other pigment is discernible in the embryo (Fig. 9, e). They are located in segment III at the posterior of a clear, unpigmented area which extends to the tip of the head (see Fig. 10A, B, e, ua).

Close inspection reveals that the eye is actually compound, comprising a smaller anterior eye coalesced with a larger posterior eye (Fig. 9B, C). Such a compound eye was earlier depicted in the original description of Placobdella hollensis (Whitman, 1892). The consensus is that a compound eye is characteristic of the genus Placobdella, but this character has not been demonstrated in many species of this genus.

Accessory 'eyes'. An unexpected finding in this study is that some adult specimens collected in disparate locations in the Albemarle region display what is reminiscent of accessory 'eyes' in the head and neck regions (Fig. 10A, $\mathrm{B}, \mathrm{ae})$. They comprise concentrations of dark pigment on the a 2 annulus metamerically along a paramedial line. In the various specimens the most anterior of these accessory 'eyes' occur on segments V or VI, and extend posteriorly to segments VIII, IX or X. It is not known if they contain photoreceptive cells. Interestingly, the venters of such individuals often display a pair of vague thin paramedial lines (Fig. 10C, vs). 


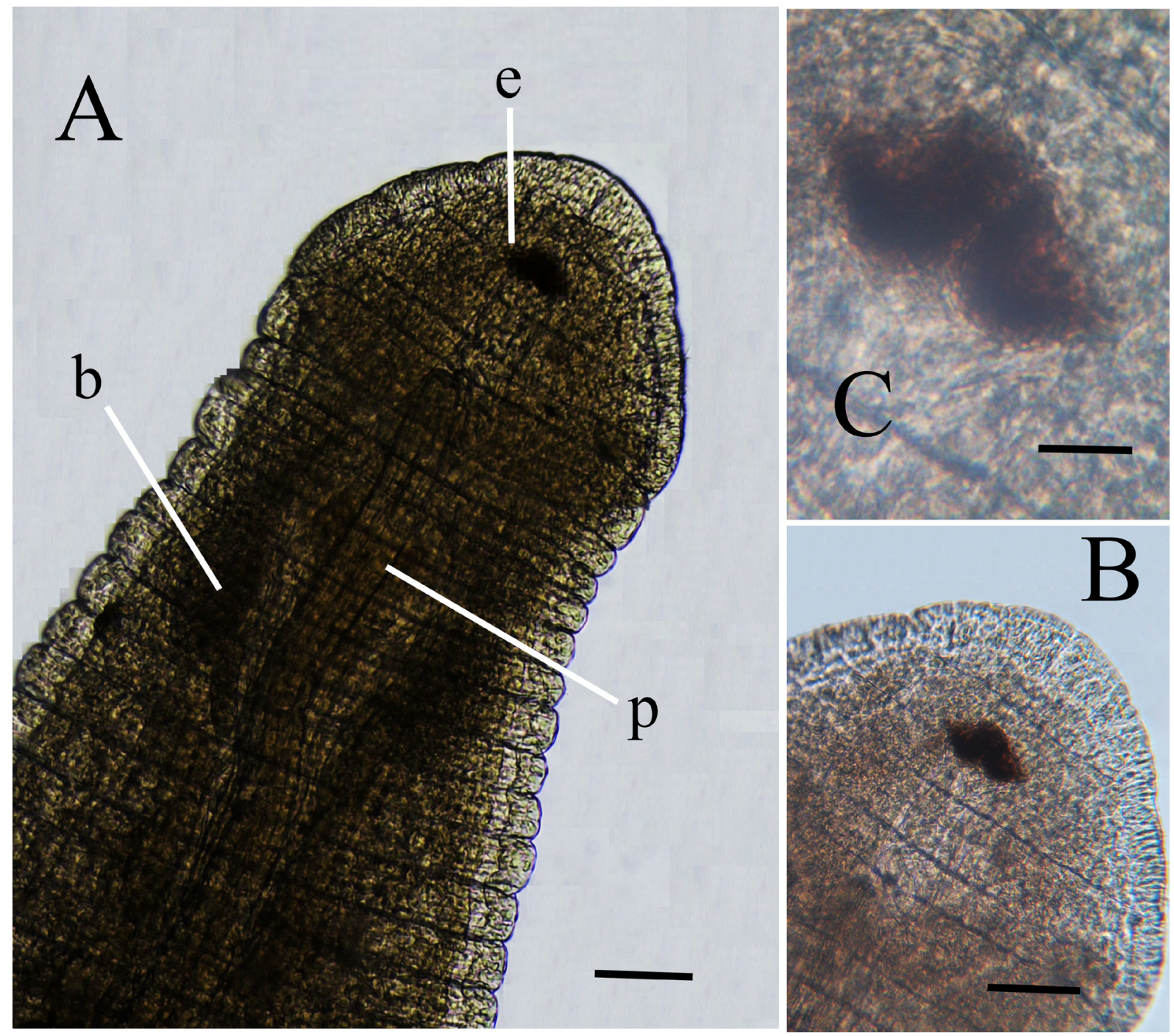

FIGURE 9. The eyes of the Albemarle turtle leech develop remarkably early in the embryo, long before any other pigment is discernible. Shown are the eyes of an early embryo (4.5 mm, PM-9) at different magnifications. A, head region showing one apparent pair of contiguous eyes. B, C, higher magnifications reveal the eyes are actually compound, each comprised of a smaller anterior and larger posterior eye. Scale bars: A, B, $0.1 \mathrm{~mm}$; C, $20 \mu \mathrm{m}$.

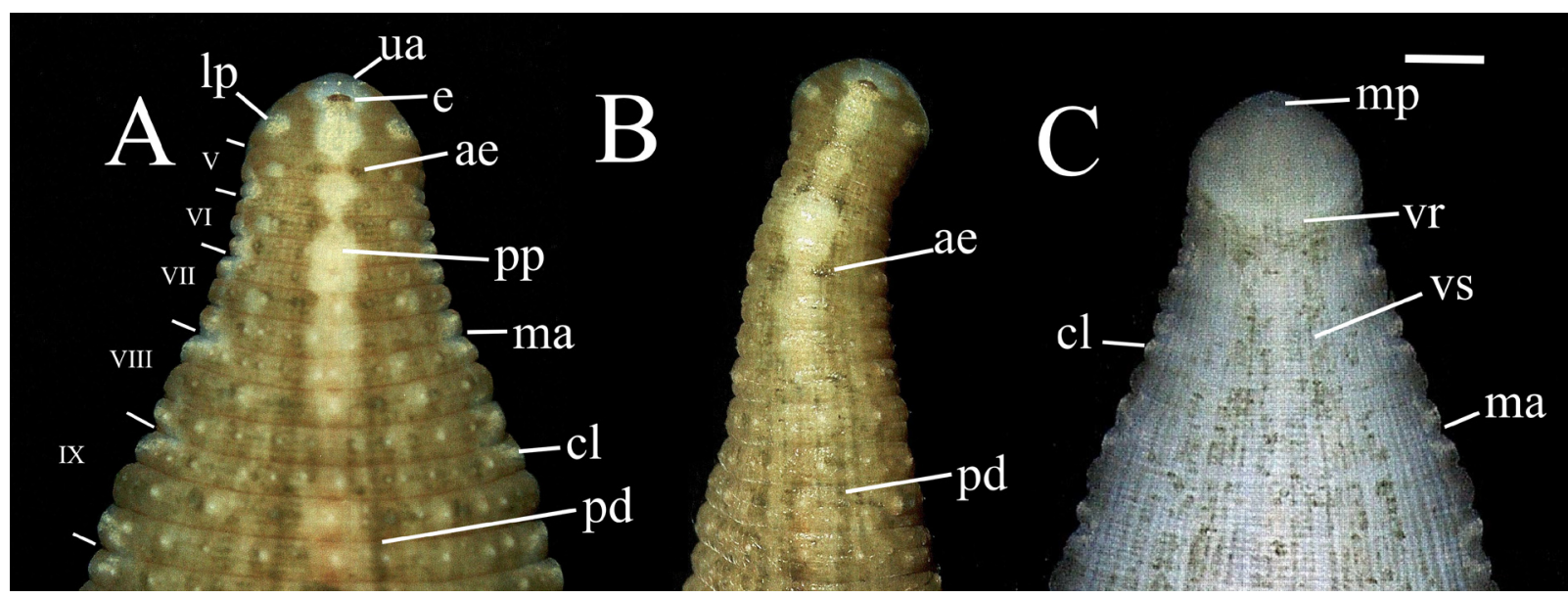

FIGURE 10. Accessory 'eyes' as shown here are strongly expressed in about one-third of the Albemarle turtle leeches. Shown are close-ups of the head regions of two individuals. A, C, dorsal and ventral views, respectively, of specimen (PM-15a). B, dorsal view of extended specimen (PM-14b). Such heavily pigmented individuals typically display paramedial stripes on dorsum (pd) and on venter (vs), respectively. Scale bar: $1.0 \mathrm{~mm}$. 
Accessory 'eyes' are strongly expressed in $36 \%$ of adult individuals examined in this study $(\mathrm{N}=11)$, more or less discernible but easily overlooked in $55 \%$ of individuals, and absent in $9 \%$ of individuals. In that accessory 'eyes' are not present in all specimens or only poorly expressed in others, this peculiar feature cannot be considered characteristic of the Albemarle turtle leech.

Until now accessory 'eyes' have been considered a unique, species-specific character of the aforementioned $P$. hollensis, originally described from coastal Massachusetts. The Albemarle specimens differ morphologically and behaviourally from $P$. hollensis as recently redescribed by Moser et al. (2014a, 2017).

Peduncle (pre-anal segments XXV-XXVII). The three pre-anal segments XXV-XXVII constitute a distinct region, herein called peduncle for convenience (Fig. 11). This peduncle is the functional interface between the muscular caudal sucker and the main body of the leech. As such it undergoes appreciable extension and flexion, requiring complex musculature. The circumferential narrowing of the peduncle varies considerably from barely noticeable (Figs. 3A, 11A) to a waist-like constriction (Fig. 11B). One interpretation for this variability is that in life narrowing of this region is transitory and reflects state of extension at time of preservation.

The peduncle is the only part of the body of this species which manifests some variation in annulation, possibly linked to its extensibility. Segment XXV is typically comprised of two annuli, a larger annulus XXV(a1+a2) followed by a smaller XXVa3 (Fig. 11A, B), but infrequently segment XXV is a single, undivided annulus XXV(a1+a2+a3). On the other hand the next segment XXVI is nearly always comprised of a single annulus XXVI(a1+a2+a3) but rarely a distinct but narrow annulus is discernible XXVIa3. The last body segment XXVII is invariant and interpreted as one large subdivided annulus at the centre of which is the anus (Fig. 11B, an). A peculiar pre-anal dark spot, typically located at XXV/XXVI, occurs persistently in some specimens.
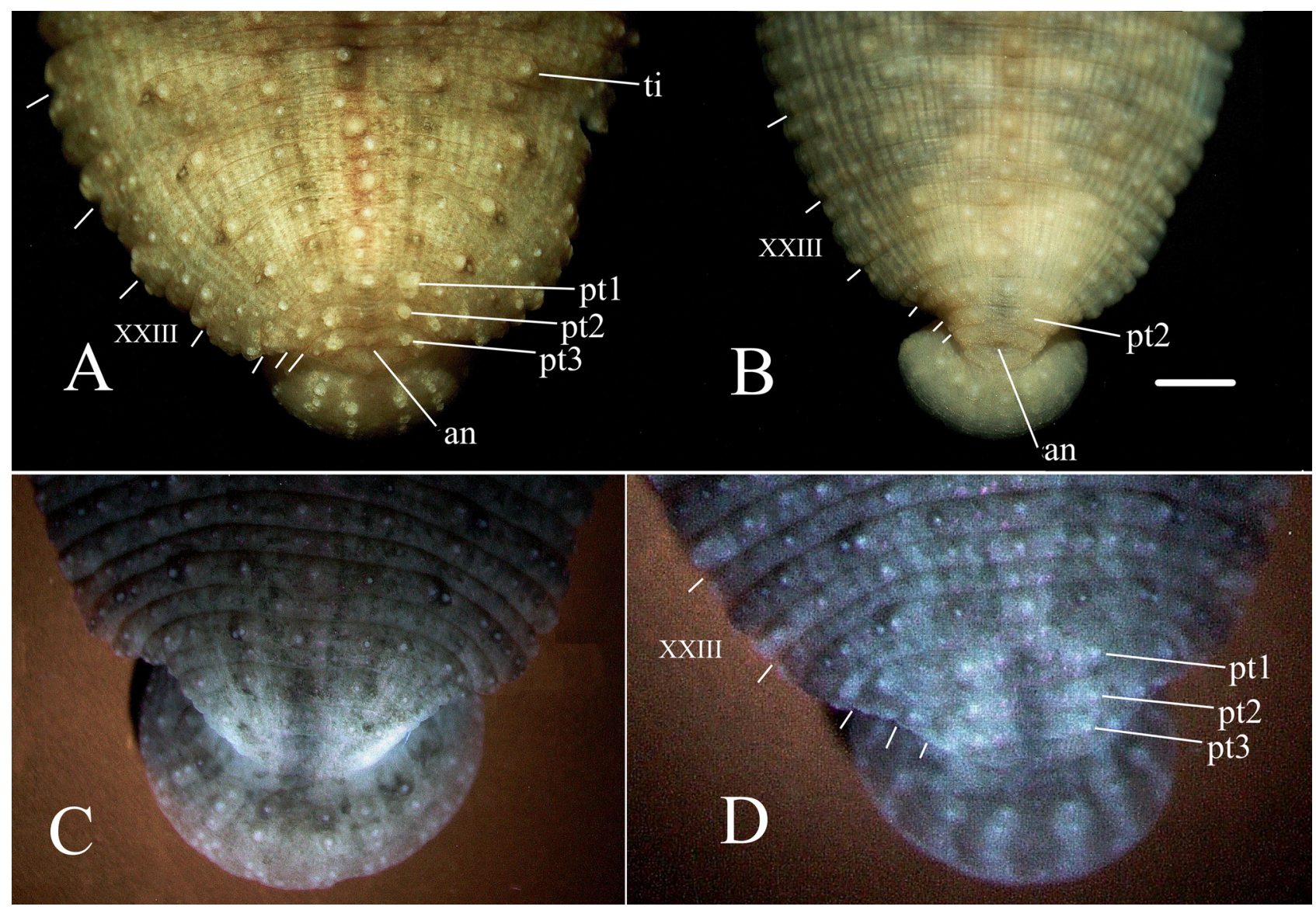

FIGURE 11. The last three body segments (XXV-XXVII) of the Albemarle turtle leech constitute the peduncle. A, specimen (PM-21a) showing typical configuration of pre-anal tubercles (pt1-pt3), a characteristic of this species. B, atypical specimen (PM-1a) with a distinctive narrowing of the peduncle as fixed during extension of the body. C, D, under ultraviolet light. C, fluorescence restricted to margins of this specimen (PM-14b). D, fluorescence primarily confined to tips of the pre-anal tubercles in this specimen (PM-14d). Scale bar: $1.0 \mathrm{~mm}$. 
The presence of three pairs of uniformly prominent pre-anal tubercles in paramedial position in segments XXV-XXVII, respectively, is remarkably constant in virtually all specimens in this study (Fig. 11A, D, pt). Accordingly, this configuration must be considered characteristic of the Albemarle turtle leech. However, similar and sometimes variable pre-anal tubercles are reported in some other species of Placobdella (Moser et al. 2013; Moser et al. 2014a,b; Moser et al. 2016; Moser et al. 2020; Richardson et al. 2017). Therefore, pre-anal tubercles per se are not taxonomically diagnostic of the Albemarle leech.
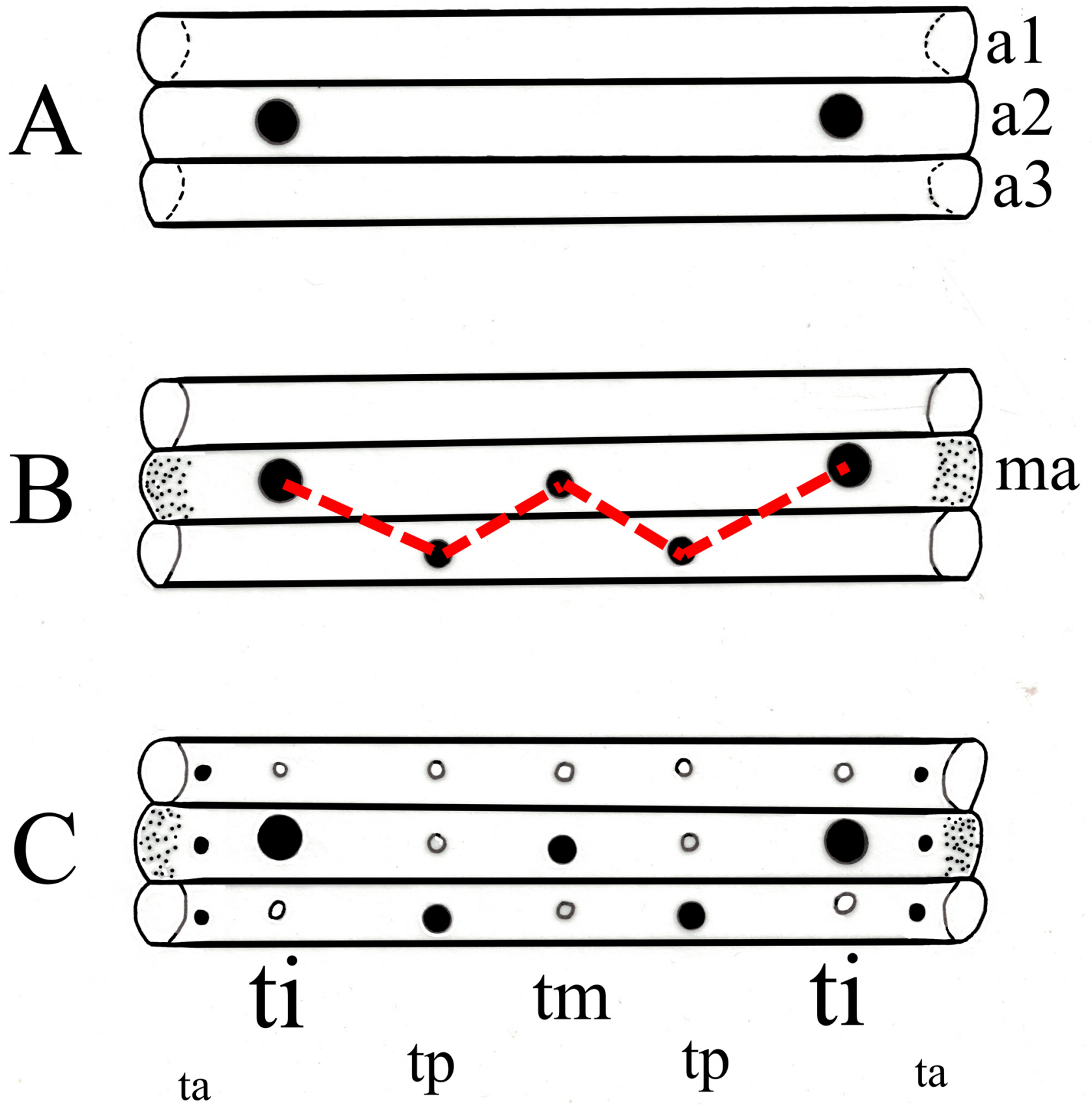

FIGURE 12. This scheme summarises appearance of key tubercles during development of the Albemarle turtle leech. Depicted are dorsal views of a mid-body segment, comprised of three annuli a1, a2 and a3, respectively. A, pre-feeding embryo (5-7 mm). B, post-feeding juvenile $(10-15 \mathrm{~mm})$. C, heavily tuberculated adult $(20-40 \mathrm{~mm})$. The intermediate tubercles (ti) arise first on the $\mathrm{a} 2$ annulus, and remain most prominent throughout life. Soon thereafter, tubercles arise in medial position ( $\mathrm{tm}$ ) on the a2 annulus, and in paramedial position (tp) on the a3 annulus. The indicated tubercles constitute a flattened ' $W$ ' configuration on each segment (red dashes), a taxonomically useful character specific to this species at virtually all stages of its life cycle. Together these respective tubercles constitute five longitudinal rows on the dorsum (see also Fig. 15A, B). 
Unfortunately, the functional significance of these pre-anal tubercles is unknown. In this context some individuals are peculiar in that the peduncle fluoresces under ultraviolet light. This response is especially intense along the margins of this region (Fig. 11C) or at the tips of the respective pre-anal tubercles (Fig. 11D).

The peduncle and its presumptive pre-anal tubercles arise very early in development. Unlike mid-body tubercles of segments XII-XXIV, as discussed below, the pre-anal tubercles of segments XXV-XXVII are not contiguous with underlying crop caeca in that the latter are absent in this body region.

Dorsal tubercles. Arrangement of tubercles in linear rows along the full length of the dorsum is the most species-specific external character of the Albemarle turtle leech (Figs. 3A, 7A-C, 15A, B, ti, tm, tp). Furthermore, this diagnostic arrangement is recognizable very early in development (see Figs. 13B, 14B, C, 15C, ti). Of taxonomic significance, the dorsal tuberculation of the Albemarle leech differs fundamentally from the outgroup species $P$. parasitica in its lack of prominent tubercles (PP-4) (however, see Taxonomic discussion).

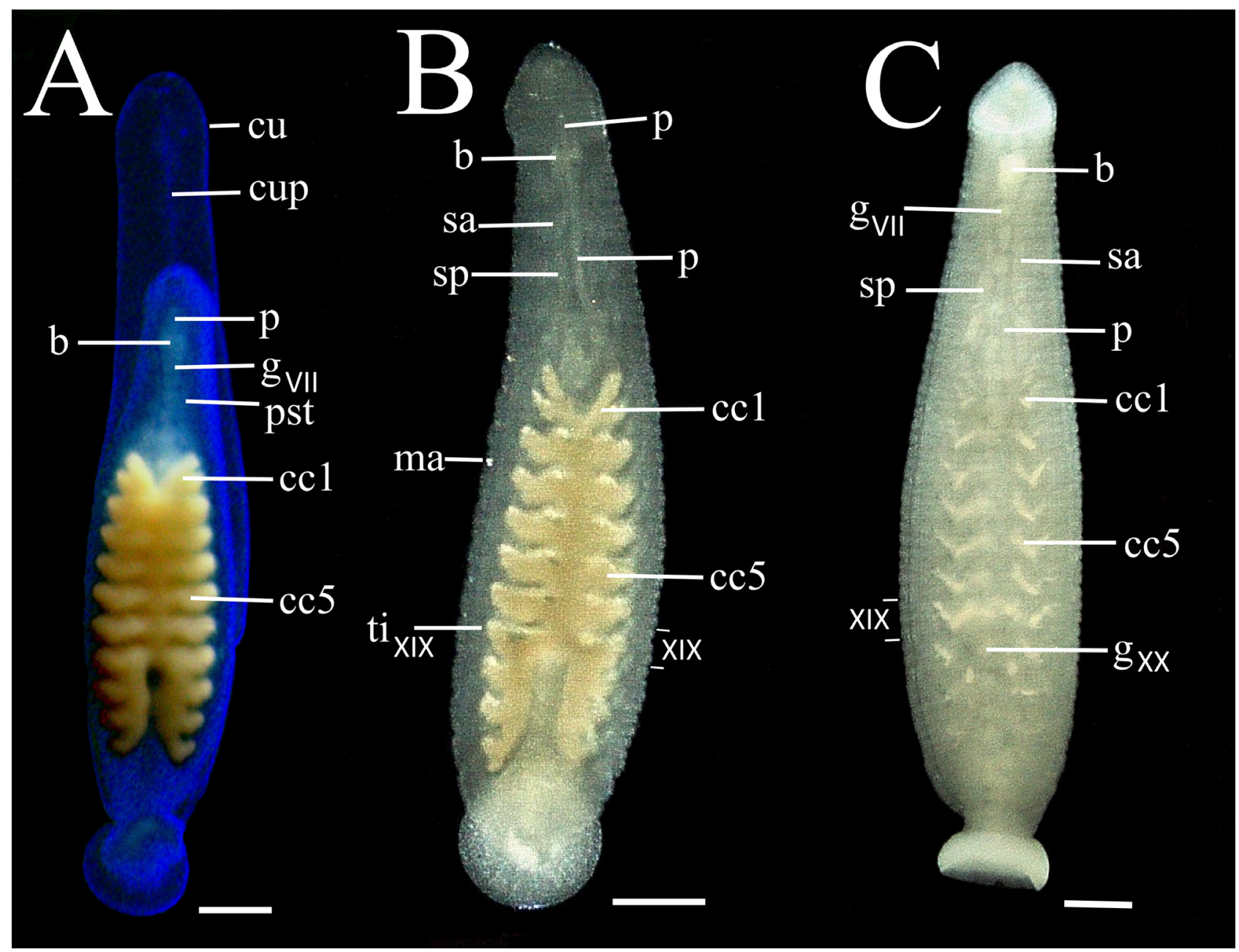

FIGURE 13. Early development of the Albemarle turtle leech. Shown are unfed, unpigmented embryos of varying ages depicting progressive changes in foregut and crop caeca. A, $4.4 \mathrm{~mm}$ (PM-15e), ventral view. B, $4.8 \mathrm{~mm}$ (PM-6b), dorsal view. C, 6.0 $\mathrm{mm}$ (PM-15h), ventral view. In specimen A the cuticle (cu) separated from the anterior part of the body during preservation. The proboscis (p) is already relatively long and penetrates through the brain (b). The relative length of the proboscis is corroborated by the long cuticle lining the proboscis sheath (cup) emerging from the mouth. Scale bars: $0.5 \mathrm{~mm}$.

In mature specimens collected during the breeding season the number of linear rows are: 5 distinct rows (9\%), 5-7 indeterminate rows $(18 \%)$ and 7 distinct rows $(73 \%)(\mathrm{N}=11)$. The relative positions of the main rows of tubercles in each segment are geometrically highly conserved and accordingly are considered to be taxonomic significant (Fig. 12). As a rule an intermediate, and most prominent, row is positioned on the a2 annulus on each side of a segment. The single median row is also positioned on the a 2 annulus, at the dorsal midline. The paramedian row on each side is positioned one annulus behind, on the a3 annulus. As a consequence these five particular tubercles are arranged invariably in a characteristic flattened ' $\mathrm{W}$ ' configuration confined to each mid-body segment (Fig. 12B, 
red dotted lines). Small paramarginal tubercles are arranged in an ill-defined row near the margins on most consecutive annuli. These marginal tubercles are especially prominent in mature adults as if they serve a function during brooding when the margins of the body turn protectively inward.

In this species tuberculation generally increases with size and maturity but the characteristic linear arrays and flattened ' $W$ ' configuration are always discernible in post-hatching individuals in spite of differential pigmentation and extraneous tubercles. In highly tuberculated individuals any or all of the respective rows may have additional, less prominent tubercles, sometimes on each consecutive annulus in linear sequence. In some cases the tubercles in a given row are very regularly arranged (Figs. 3A, 7A), whereas in others the tubercles are not so strictly aligned (Fig. 7B, C).

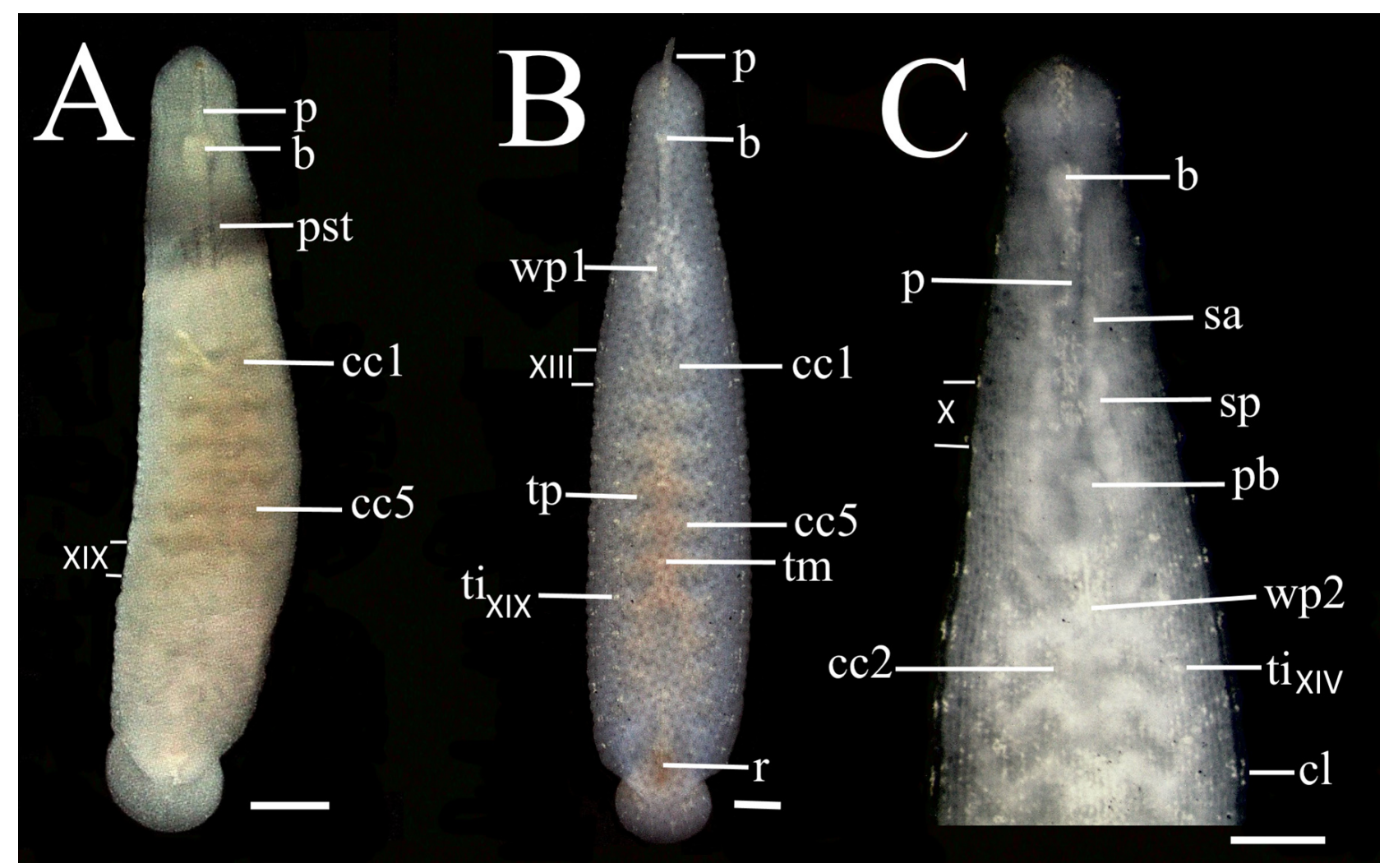

FIGURE 14. First feeding in the Albemarle turtle leech. Shown are three pre-juvenile individuals collected soon after taking their first blood meal on a turtle host. Their teguments are still transparent and the body shape is cylindroid. A, 5.0 mm (PM-11a) on Chelydra serpentina. B, 8.3 mm (PM-26) on Chrysemys floridana. C, 7.8 mm (PM-24a) on Kinosternum odoratus. Specimen A was collected within hours of first feeding and already had diluted blood in its crop. The intermediate rows of tubercles on the a 2 annulus were discernible but do not show up in this image. In specimen B the tip of its lengthy proboscis protrudes from the apical mouth. The darkened rectum indicates some digestion of blood had already occurred. This correlates with the faintly pigmented tegument of this specimen. In specimen $\mathrm{C}$ the crooked proboscis and compact salivary glands are visibly well developed at this stage. Scale bars: $0.5 \mathrm{~mm}$.

The sucker varies considerably in the degree of dorsal tuberculation, from virtually no tubercles to several rows of prominent tubercles (Fig. 11). Accordingly, tuberculation of the caudal sucker is not taxonomically significant in this species.

Body shape. Adults are invariably flat and broad (see Figs. 3, 7, 15A). In contrast, hatchlings and juveniles have a different body shape (Figs. 13, 14, 15C). At $5 \mathrm{~mm}$ the body is nearly linear and rounded (tubular) in cross-section. At this stage the caudal sucker is relatively large compared to mid-body width and is more or less continuous in line with the body (i.e., terminal). By about $10 \mathrm{~mm}$ the body has expanded laterally to approach the flattened shape of the adult (Fig. 8A). Its sucker is now oriented at right angles to the body (ventral) and is relatively smaller compared to body width. This change in sucker orientation reflects a change in function of the caudal sucker from a holdfast organ to one of locomotion.

The change in body shape has taxonomic consequences. For example, in this study of the Albemarle turtle leech 
the adults $(28-45 \mathrm{~mm})$ have an average ratio of caudal sucker/ maximum body width of $0.34(\mathrm{~N}=22$, range 0.24 0.48). This falls within the lower end of the range of $0.32-0.47$ given for P. multilineata by Richardson et al. (2017). However, young individuals $(4.4-7.8 \mathrm{~mm}$ ) in this study have a caudal sucker/ maximum body width ratio of 0.67 $(\mathrm{N}=19$, range $0.60-0.86$ ). This is well outside the range for all of the seven species of Placobdella in Richardson et al. (2017). In other words, in the case of the Albemarle leech, body shape and relative size of the caudal sucker only have taxonomic meaning in fully grown adults. In practice this is essentially the average length of brooding individuals. However, in that body shape, and its concomitant meristic features, are not consistent throughout all life stages, it is not a reliable diagnostic character in this species.

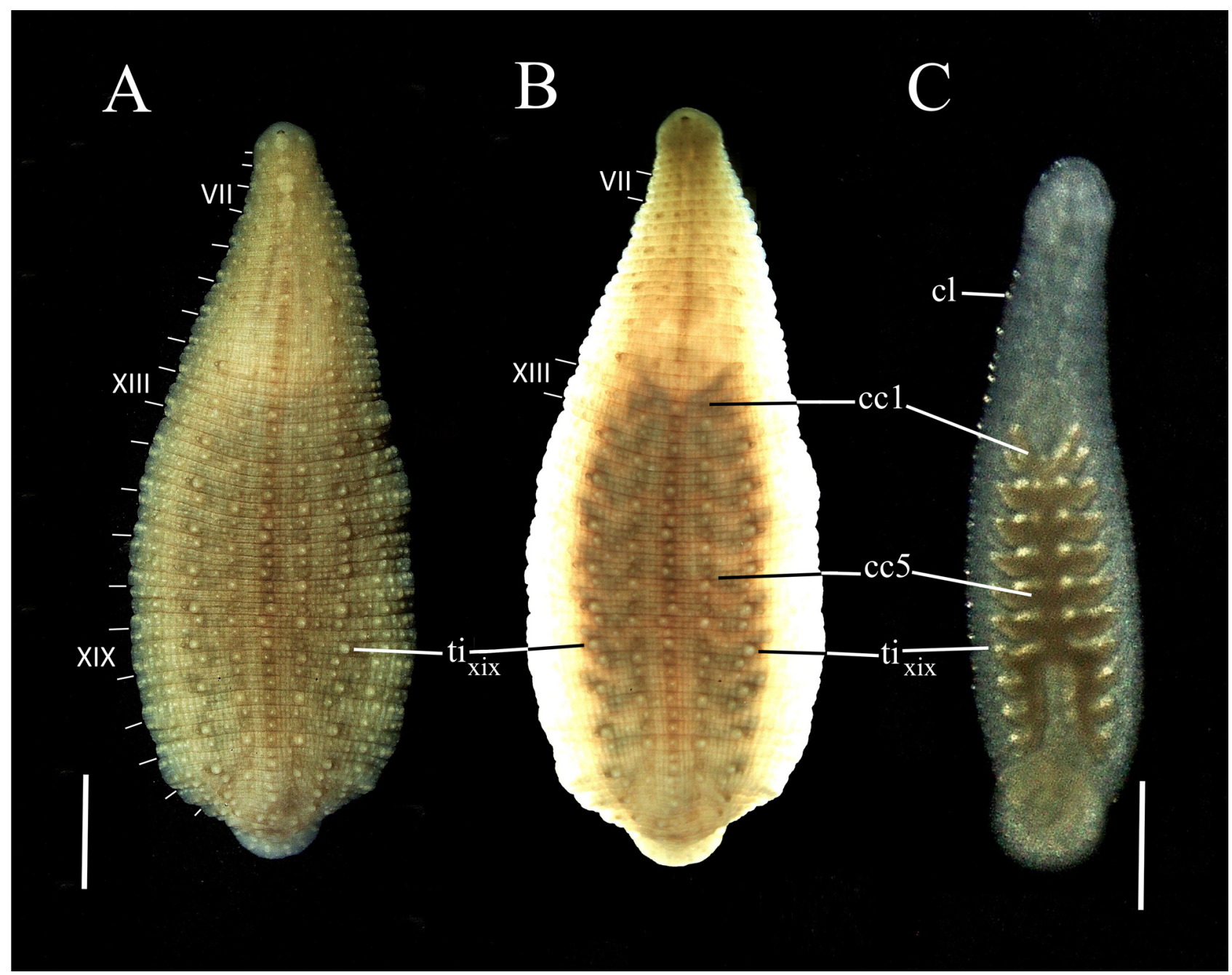

FIGURE 15. The multilinear pattern of dorsal tubercles in the Albemarle turtle leech correlates with the underlying crop caeca. For comparative purposes the intermediate tubercle (ti) of segment XIX is labelled in each respective image. A, orderly pattern of five rows of dorsal tubercles of an adult individual (PM-6). B, same individual as A under intense transmitted light showing the respective dorsal tubercles in relation to underlying blood-filled crop caeca. $\mathrm{C}$, unfed embryo (4.8 mm) brooded by the adult in A, B, showing presumptive tubercles linked to the same respective crop caeca. A, reflected LED light. B, C, transmitted LED light. Scale bars: A, B, $5.0 \mathrm{~mm}$; C, $0.2 \mathrm{~mm}$.

\section{Internal features}

Dissections are carried out on a geographically diverse sample of six individuals to evaluate variability of key internal features. Specimens dissected in this study were all adult $(32-44 \mathrm{~mm})$, with the exception of one juvenile (6.5 mm, PM-13c). The foregut of the archetype specimen (Fig. 4) serves as a baseline for meaningful comparisons. Development of the digestive tract is easily followed through the transparent teguments of embryos and early juveniles.

Proboscis complex. Invariably, the Albemarle turtle leech has an exceptionally long tapering proboscis which sets this leech apart from all other species in the Outer Banks region, with the exception of the outgroup species $P$. 
parasitica (see Taxonomic discussion). Its proboscis is so long that its proximal (posterior) end crooks to fit into available space of the foregut, and its tapering anterior end passes through the brain (circum-proboscis commissure) to terminate near the mouth pore (Figs. 4, 9A, p). In only one aberrant, exceptionally large individual (PM-12, $44 \mathrm{~mm}$ ) is the posterior crook absent, and its anterior tip terminates behind, rather than anterior to, the brain. This specialised proboscis complex is undoubtedly a biological adaption to feeding through the tough skin of turtles to obtain a blood meal, at all stages of its life cycle. Interestingly, the crooked proboscis develops very early in the embryo (Figs. 13, 14, p). In the outgroup species P. parasitica the proboscis of the hatchling is also long and recurved (PP-4b, $6 \mathrm{~mm}$ ).

Salivary glands. All dissected specimens invariably have two pairs of compact salivary glands, an anterior medial pair and a larger posterior pair. The thin ductule from the anterior gland joins the much thicker ductule from the posterior gland well before the common ductule enters the base of the proboscis. This confluence is roughly one-third the length of the posterior ductule, i.e., closer to the proboscis than to the posterior gland.

The dissected specimens differ from the archetype specimen (Fig. 4) in certain respects considered to be taxonomically insignificant for the purpose of this study. The caudal extension of the posterior salivary gland varies in different individuals from segments XII, XIII to XIV, respectively. The maximum size of individual salivary cells, as randomly measured, varies from $90-320 \mu \mathrm{m}$. The ductule of the anterior gland varies considerably with respect to how many and how far the individual salivary cells adheres along the ductule, but in all cases these cells more or less disappear before reaching the confluence with the ductule from the posterior gland. In one specimen part of the anterior gland wraps snugly onto the proboscis sheath.

Salivary cells are discernible early in the embryo. At $4.4 \mathrm{~mm}$ the salivary cells are not fully compact, i.e., the salivary glands are still presumptive (Figs. 13A, pst). However, from $4.8 \mathrm{~mm}$, the compact nature of the salivary glands is clearly discernible (Figs. 13B, C, 14C, sa, sp).

Mycetomes. In all cases the oesophagus proceeds anteriorly from the base of the proboscis to the ventral floor where it bends to proceed posteriorly. Location of where the oesophagus intercepts the ventral floor varies in different individuals from anterior to $\mathrm{g}$. $\mathrm{X}$, just posterior to $\mathrm{g}$. $\mathrm{X}$ to as far as $\mathrm{X} / \mathrm{XI}$, respectively. A pair of mycetomes arise from the oesophagus near the ventral floor posterior to the bend. In the region between ganglia XII and XIII the oesophagus in various individuals is either more or less straight, displays a single loop, or is distinctly convoluted, respectively.

Mycetomes in the various dissected individuals are very similar to those described in the archetype specimen, especially in position and saccular structure (Fig. 4A, my). However, they do vary in size and integrity from poorly defined to conspicuous. Similar saccular mycetomes occur in the outgroup species P. parasitica (Moser et al. 2013, fig. 5) and therefore this structure is not diagnostic of the Albemarle turtle leech. In fact the conserved nature of the mycetomes corroborates the growing consensus that a single pair of saccular mycetomes (bacteriomes) is characteristic of species of the genus Placobdella. These structures are known in other species to harbour endosymbiotic bacteria which appear to be vital for the nutrition of these sanguivorous glossiphoniids (Siddall et al. 2004; Kvist et al. 2011).

An open question is how these endosymbionts are transmitted to the mycetomes, although co-evolution from the parent seems likely based on bacterial phylogenetics (Manglicmot et al. 2020). In this context observations on the early development of mycetomes in the Albemarle turtle leech may be relevant. In some embryos (4.2 mm long) the earliest manifestation of this region is a darkly silhouetted, somewhat wavy oesophageal tube linking the base of the proboscis to the crop. Later $(5.0 \mathrm{~mm})$, a dark tube or pouch (mycetome) is discernible from either side of the oesophagus. It is not clear why the oesophagus and the contiguous mycetomes appear early as dark silhouettes, contrasting the otherwise light background tissue; nor is it clear why these silhouetted structures are not apparent in all embryos at a given stage. The possibility that microorganisms found in the mycetomes of this species arise exogenously from the microbe-rich aquatic environment cannot be formally eliminated by these observations. In this context the proboscis is well developed before the mycetomes are detectable, and could conceivably serve as a conduit for microbes from the outside (see Figs. 13A, cup, 14B, p).

Note: The paired mycetomes in a species tentatively identified as $P$. multilineata from coastal South Carolina were erroneously identified by Sawyer \& Shelley (1976, fig. 4) as a third pair of salivary glands.

Development of midgut. In marked contrast to the precocious foregut (proboscis complex), the midgut (crop and caeca) is relatively late to develop. Developmental stages of the embryo can be defined by the degree of branching of the caeca, as follows. To assist future researchers these stages are expressed as days since laying (Day 0), 
with approximate lengths of the embryo as a guide. In the earliest examined embryo, at Day 4 (4.2 $\mathrm{mm})$, the midgut is essentially a simple, yolk-filled tube located in segments XIII-XIX, inclusively. Presumptive caeca are seven stumpy lateral diverticula, the largest being the first one (XIII), located behind the well-developed foregut. There are no posterior crop caeca at this early stage. On Day $5(4.4 \mathrm{~mm})$ the first presumptive caecum bifurcates slightly (Fig. 13A, cc1). Soon thereafter, the next five presumptive caeca broaden laterally without bifurcating. The seventh caecum emanating from segment XIX extends ventro-caudally to form a simple posterior caecum which bears four lateral undivided diverticula (Fig. 13A). On Day $6(4.8 \mathrm{~mm})$ the first caecum becomes forked such that the anterior portion extends forward into segment XII (Fig. 13B, cc1). The next five caeca extend as finger-like projections such that each first proceeds posterolaterally and then sharply anterolaterally at near right angles, i.e., to form a ' $\mathrm{V}$ ' shape on each side of a segment, without branching at the tips (Fig. 13C, cc5). The seventh or posterior caecum has four straight, relatively stubby projections, the last of which is slightly forked at this stage (Fig. 15C). On Day 7 (5.9 $\mathrm{mm}$ ) the tips of the first six caeca are distinctly forked (Figs. 14C, cc2, 15B, cc5). The seventh or posterior caecum has elongated such that there is noticeable distance between each of the lateral projections. By $10 \mathrm{~mm}$ in some free living individuals a dark substance, presumably blood, silhouettes multi-branched caeca similar to that described in the following section for adults (Figs. 6B, 15B, cc5).

' $W$ ' configuration of the crop caeca. Adults are dorso-ventrally flattened such that when replete with blood the crop caeca display a finely branched two-dimensional configuration diagnostic of this species (Figs. 3B, 6B, $\mathrm{C}, 15 \mathrm{~B}, \mathrm{cc5}$ ). In all blood-filled adults examined in this study the crop is comprised of seven pairs of bilateral caeca centred in segments XIII-XIX, inclusively. The first pair of caeca, originating from segment XIII, extends anteriorly and laterally into segment XII. The next five pairs of caeca are more or less confined laterally in their respective segments. From near the midline of each of these segments the caecum extends laterally and posteriorly, and then turns sharply almost at right angles laterally and anteriorly. Lateral to the intermediate tubercles, the ends of the caeca bifurcate, and even smaller digitiform branches extend nearly to the margins, as if filling available space. The seventh or last pair of crop caeca originate from segment XIX and extend posteriorly on each side as far as segment XXII or so. Each of these 'posterior crop caeca' has four lateral branches, in segments XIX-XXII, inclusively. These divide further in correspondence with branching of the mid-body caeca.

The overall result is that the major arms of the caeca on each side together configure the letter ' $\mathrm{W}$ ' in each mid-body segment. This diagnostic 'W'-shaped configuration of crop caeca arises as early as by Day 6 (Fig.13C), but the full marginal branching appears primarily in adults replete with blood, not unlike a fluid-filled glove with narrowing and branching fingertips.

The current study reveals an unexpected link between the ' $\mathrm{W}$ '-shaped crop caeca and the linear configuration of the dorsal tubercles described earlier. Specifically, the alignment of the most prominent tubercles on the dorsum spatially corresponds very tightly with the configuration of the underlying crop caeca (Fig. 15A, B, ti). This link arises very early during development (Fig. 15C, ti) and is manifested ontogenetically by an apparent cellular 'bridge' connecting the incipient tubercles with the presumptive caeca in the early embryo (see Figs. 13B, 15C, ti). The biological significance of this correlation, if any, remains unclear. It is not known, for example, if this correlation implies a functional link between the tubercles and the crop caeca at any stage of development.

It is developmentally noteworthy that crop caeca lie only in segments XII to XXIV, inclusively. However, the intermediate row of tubercles occur in the cardinal metameric positions as far anteriorly as segment VI, i.e., well beyond influence of the crop (Fig. 15B). In developmental terms, one interpretation is that the 'organizer' of the multilinear pattern in this species is attributable to a factor(s) in the embryonic dermis which induces the underlying crop during development, rather than the reverse (see Arias \& Steventon 2018), but this remains speculative.

From a taxonomic perspective, it is noteworthy that the foremost character which diagnoses this species externally ('W' configuration of tubercles) correlates so intimately with a character which diagnoses this species internally ('W' configuration of crop caeca) (Fig. 15). Furthermore, when the foregut is considered it is intriguing that all three of the specific-specific characters discussed in the taxonomic section below are linked to the digestive system, either directly or indirectly.

\section{Biology}

\section{Taxonomic overview}


Taxonomy of the Albemarle turtle leech is most meaningful in the context of the biology of this species. Of the twenty or so species of Hirudinea encountered in this study the Albemarle turtle leech is arguably the best adapted to living in the extreme conditions of a swamp ecosystem, aided by its almost commensal relationship with turtles for food, transport and shelter. In fact, this species appears to feed exclusively on turtles, there being no evidence in this study of its feeding on other reptiles, amphibians, fish or humans.

In this context, the central role of feeding in the biology of this species must be emphasized. Anatomically, this is manifested foremost by a long, tapering proboscis, the most highly specialised feeding apparatus of any leech species in the Outer Banks region, with the exception of the outgroup species P. parasitica (see Taxonomic discussion). Less obviously, its pigment patterns are also intricately linked to feeding in that, for example, the first blood meal 'triggers' initial deposition of brown pigment (see Fig. 14B). As a rule young individuals with no sign of blood in the crop are transparent and lack pigment altogether, apart from the eyes. On the other hand those juveniles in the same cohort with even a hint of blood in the crop display a faint brownish background. By way of specific example, one unfed individual $(6.0 \mathrm{~mm})$ encountered in this study lacks pigment (PM-13f), whereas another $(5.0 \mathrm{~mm})$ in the same cohort had fed slightly, based on its pinkish crop contents. As a result the latter individual displays a very faint brown background, as well as an incipient mid-dorsal stripe in anterior segments VII-X (PM-13g).

Progressive darkening with age. Deciphering the taxonomy of the Albemarle turtle leech has been challenging due in part to pigmentation and other changes during growth and development. As revealed in this study this species is remarkable in the Hirudinea in that it displays three distinguishable life forms in terms of morphology and behaviour, each adapted to a different aspect of its life cycle. These phases are outlined below:

Pre-feeding phase (up to $5 \mathrm{~mm}$ ). The somewhat rounded body is transparent from lack of pigmentation and thereby camouflaged by near invisibility (Figs. 13A, B, 15C). Behaviourally, the individual is very active and capable of swimming on rare occasions. Individuals of this phase are found only on the venter of its parent, or on a turtle prior to, or immediately after, feeding.

Juvenile phase $(7-25 \mathrm{~mm})$. Abrupt onset of the juvenile phase correlates with its first blood meal on a turtle. The body is more dorso-ventrally compressed and wider, and displays bold dark and light metameric pigment patterns (Figs. 6A, 8A). The juvenile is fairly active when in pursuit of food, and camouflaged against variegated surroundings, likely including its turtle host.

Mature phase $(28-45 \mathrm{~mm})$. The very flat body of the mature adult is uniformly dark (Figs. 3A, 7, 15A). This clearly serves as camouflage for the leech during brooding, especially effective in tea-coloured swamp water. In terms of body shape, size, cryptic coloration and midrib-like stripe this mature phase is reminiscent of a waterlogged leaf. The gravid adult is reticent and relatively immobile. Speculatively, onset of this phase appears to correlate with oogenesis and subsequent brooding.

By way of summary, with age the animal becomes darker such that stripes and patterns become obfuscated, adding to taxonomic uncertainty, especially if relying primarily on superficial characters for identification. At the physiological level the progressive darkening of this species is interpreted as accumulation of metabolic products from digestion of blood, similar to that shown by Bradbury (1959) for Hirudo medicinalis Linnaeus.

Feeding strategy. After feeding, it is not clearly understood from data in this study whether the growing leeches (7-25 mm) typically remain on the turtle or periodically get off or both. In retrospect this gap is due in part because no methodical attempt was made in this study to survey aquatic turtles for leech infestation. While occasional juveniles are encountered free-living (Figs. 6,8), others in the same cohort may remain on the turtle host. A case in point is the discovery of approximately 50 post-juveniles (PM-22) in mid-June, on a single snapping turtle C. serpentina. The latter had been captured while moving from a smaller to a larger body of water, i.e., to judge from context apparently not in the process of laying eggs. Based on uniform size these leeches may constitute a single cohort, many of which were dorsal on the still-damp carapace. In other words it is possible the growing juveniles spend much time on aquatic turtles, but this needs further study.

In early summer turtles of several species are often encountered crawling on land, a behaviour typically associated with egg-laying at this time of year. In this study such turtles are generally devoid of leeches, but some turtle species appear to be more prone than others to harbouring leeches. For example, in the period 3-23 May 2018 in Gum Neck, Tyrrell County, the following turtle species encountered on land were examined for leeches: mud turtle Kinosternum subrubrum (Bonnaterre) $(18.2 \%$ infected, $\mathrm{N}=11)$, Florida cooter Pseudemys floridana (LeConte) $(0 \%, \mathrm{~N}=1)$, painted turtle Chrysemys picta (Schneider, 1783) $(0 \%, \mathrm{~N}=6)$, snapping turtle C. serpentina $(0 \%, \mathrm{~N}$ $=1)$, musk turtle Sternotherus odoratus (Latreille, 1801) $(0 \%, \mathrm{~N}=1)$, spotted turtle Clemmys guttata (Schneider) 
$(0 \%, \mathrm{~N}=1)$ and box turtle Terrapene carolina (Linnaeus) $(0 \%, \mathrm{~N}=1)$. Interestingly, the infection rate varied somewhat from year to year. Thus, in precisely the same area the following year, during 12-30 May 2019, the following turtle species on land were examined: P. floridana $(50 \%$ infected, $\mathrm{N}=4)$, K. subrubrum $(14.3 \%$ infected, $\mathrm{N}=7)$ and $C$. picta $(0 \%$ infected, $\mathrm{N}=7)$.

By way of caution to future researchers, this study found evidence that the occurrence of a leech on a turtle is not proof per se that the latter serves as a food source. Namely, three adult individuals of the non-sanguivorous, snail leech Helobdella lineata (Verrill, 1874) were discovered on the plastron of a P. floridana captured on land about 15 metres from water. By general inference, turtles constitute a convenient form of transportation in these mud-bottomed swamps for both sanguivorous and non-sanguivorous species.

\section{Reproductive biology}

Breeding size. In this study the resting length of all the gravid/brooding individuals clustered tightly around a mean of $36.6 \mathrm{~mm}(\mathrm{~N}=23$; range, $28.0-45.0 \mathrm{~mm}$; standard error of the mean at $90 \%$ level, $1.8 \mathrm{~mm})$. Of unexpected taxonomic significance, the size of the Albemarle turtle leech at the time of egg-laying is a consistent characteristic of this species.

This finding proved useful in distinguishing similar species in at least one instance. For example, at one collecting station along with a typical, gravid Albemarle turtle leech (PM-21, $32 \mathrm{~mm}$ ), another superficially similar 'placobdellid' was collected at the same time. This individual was also very gravid but was conspicuously smaller $(18 \mathrm{~mm})$. Closer inspection revealed this was a different, as yet unidentified, species which displays a distinctive white nuchal ring, unlike the Albemarle turtle leech.

Mating. Mating is by hypodermic impregnation of spermatophores. This was observed in this study on only two occasions onto already gravid, recently fed individuals (PM-8, $35 \mathrm{~mm}$; PM-10, $31 \mathrm{~mm}$ ). In both cases soon after capture another individual implanted a spermatophore into the dorsal tegument of segments XIV and XVII, respectively. The structure of the spermatophore is distinctive and probably characteristic of the species. The taxonomic significance of the spermatophore cannot be pursued further here, other than point out that other workers claim spermatophores may differ in detail between species within the genus Placobdella (Whitman 1891; Moore 1953).

Breeding season. Evidence from this study indicates that breeding of the Albemarle turtle leech is seasonal, in late spring. Gravid and brooding specimens were collected on April $25(16 \%), 27(16 \%)$, May $1(4 \%), 6(8 \%)$, $12(12 \%), 13(4 \%), 14(12 \%), 15(4 \%), 20(20 \%)$ and $21(4 \%)(\mathrm{N}=25)$. Interestingly, one large individual (PM4, $39 \mathrm{~mm}$ ) was collected out of season, on October 17. This individual was remarkable in displaying six pairs of exceptionally large, whitish, spheroidal testisacs visible through the ventral body wall. Dissection confirmed this individual was not gravid.

Brooding. In the mud-bottomed swamps of the Albemarle region gravid and brooding adults are invariably found on solid substrates. Natural substrates are: under loose bark of submerged logs or on a submerged log or limb. Such brooding individuals are not only well camouflaged with dark pigmentation, they remain remarkably quiescent when disturbed. For example, one log in a shallow swamp was pulled ashore for examination. It harboured two mature individuals (one brooding, one gravid) neither of which moved until capture.

Artificial substrates are also commonly used by brooding adults and include: the underside of a board, on or in a plastic container, plastic bag, glass bottle, or a piece of submerged metal. Their proclivity for smooth surfaces and darkness explains the success of the aluminium traps in capturing still other breeding individuals (Fig. 2B).

Fecundity. Based on very limited data, this species deposits on average at least 75 (54 to 111) eggs, with larger individuals apparently producing more offspring. One relatively small individual (PM-19, $29.5 \mathrm{~mm}$ ) at the time of capture on a plastic bag was brooding 54 relatively advanced unpigmented embryos $(4.5-5.0 \mathrm{~mm})$. On another occasion a gravid leech (PM-21a. $32 \mathrm{~mm}$ ) deposited 56 yolky eggs soon after capture. On the other hand four larger adults collected together (PM-15a-d, 37.2-45.0 mm) between them bore a total of 332 embryos: one cohort consisted of 111 embryos (6.0 mm, no yolk remaining in crops); one cohort with 86 embryos $(5.9 \mathrm{~mm}$, slight yolk in crops); and two cohorts with a combined total of 135 embryos (Mean, 67.5, 4.3-4.8 mm, very yolky crops). It is not known if in the Albemarle region this species can produce more than one brood in a season, or whether they can breed in successive years.

\section{From egg-laying to first meal on a turtle}

Brooding behaviour in this species in nature can be divided into pre-hatching and post-hatching phases, as inferred 
by the stage of development of embryos on brooding adults captured daily on the aluminium traps. In this study the youngest embryos encountered on the traps were already fairly advanced. As a rule these were 4.3-4.4 mm in length and characterised by a yolky, distinctly caecate crop, including the presence of posterior caeca (Fig. 13A).

The conspicuous absence of embryos earlier in development on the traps is compatible with the interpretation that the adult is stationary from the time of egg-laying until the embryos hatch and become attached securely to the venter. This pre-hatching period is estimated to be up to 4 days, based on limited laboratory observations. In the post-hatching phase the brooding adult moves about with its young and only then is encountered on the traps.

A biological interpretation is that in nature the parent takes its young to a turtle host, affording opportunity for their first blood meal. In this study recently fed very young leeches were captured, without the brooding adult, on the following turtles crawling on land: C. serpentina (May 12, June 11), K. subrubrum (May 19) and P. floridana (May 17).

Specifically, on one occasion 11 unfed or very recently fed young were captured in the rear axils of a small $C$. serpentina on land (PM-11, 4.4-5.3 mm). These small whitish individuals were almost entirely unpigmented. Their non-yolky crops were either entirely clear, i.e., devoid of blood altogether, or very faintly diluted with blood (Fig. 14). By inference the young at first feeding ingest very little blood at a time, but it is digested rapidly. (This is in marked contrast to gravid adults which imbibe a large quantity of blood in a single meal and this is digested slowly.) On another occasion 4 young (PM-24, 6.8-7.8 mm) were found in the neck region of a K. subrubrum. Although they had some blood in their crops these cohorts were remarkably active by crawling in rapid inchworm manner following capture. The unexpectedly active behaviour of some young of this species, possibly correlating with 'hunger', is epitomised by a single individual (PM-17f, $7.8 \mathrm{~mm}$ ) which swam unequivocally for a brief but sustained period. In this study swimming was never observed in adults which are characteristically quiescent, especially when brooding. This contrasts with P. hollensis whose adults swim readily (Whitman 1892, p. 392), very unusual behaviour for species of Placobdella.

\section{Physical parameters}

Physical parameters of the waterways in which the turtle leech is known to inhabit were not investigated, apart from a few random observations. The water temperature at the time of breeding was typically about 18.6 C (range17.820.5, $\mathrm{N}=4$ ). In a drainage canal adjacent to agricultural fields the $\mathrm{pH}$ averaged 7.32 (range 6.97-7.53, $\mathrm{N}=4$ ), whereas a nearby swamp, also harbouring turtle leeches, was more acidic at $\mathrm{pH} 6.53$ (range 6.23-6.83, $\mathrm{N}=2$ ).

Oxygen probably plays an important role in the micro-distribution of several leech species in the Albemarle region (pers. obs.). At one extreme the turtle leech may have unusual tolerance for low oxygen conditions. In fact, oxygen as a limiting factor for leeches living in southern swamps has never been investigated but may have taxonomic significance. By way of speculative example, is it possible that the dorsal tubercles so characteristic of this turtle leech play an adaptive role by increasing surface area? Similar adaptations to hypoxia can be postulated also at the molecular level (Sokolova 2018), but the phylogenetic implications lie outside the scope of this paper (Galtier et al. 2009).

Oxygen levels were not measured in this study but swamps in this area are not uncommonly hypoxic due to accumulations of decaying vegetation (Speiran et al. 2015). Another physical factor dominating these swamps is precipitation. This area vacillates between submerged swamps and dry woodland, depending on seasonal rainfall (see Sawyer 2010, 168-169).

\section{Taxonomic discussion}

Taxonomic significance of the foregut. Both the Albemarle turtle leech and the outgroup species $P$. parasitica possess a highly specialised, long tapering proboscis crooked at its proximal end. However, comparison of the two species demonstrates the diagnostic importance of the proboscis complex in morphologically distinguishing these closely allied turtle leeches from the same region. Specifically, the ductules of the anterior and posterior salivary glands of the Albemarle leech join a measurable distance from the base of the proboscis to form a clear and unmistakable common ductule, whereas the respective ductules of $P$. parasitica enter the base of the proboscis independently, or at most barely abutting. The taxonomic significance of this distinction cannot be overemphasised. In fact, this precise difference in salivary ductule configuration also distinguishes two sympatric species of Placobdella in the coastal plain of South Carolina (Sawyer \& Shelley 1976, p. 71). 
Furthermore, the proboscis of $P$. parasitica, at least in Albemarle specimens examined, consistently has a peculiar asymmetrical deflection at segment IX. In a fully mature specimen (PP-4a) this deflection constitutes an improbable $360^{\circ}$ loop of the proboscis in this segment. In smaller specimens this deflection is less developed, appearing as a sizeable lateral curve (PP-2), or simply as a slight but distinct deviation at IX (PP-1). In contrast, the proboscis of the Albemarle leech is straight and symmetrical all along its length.

Finally, the salivary glands of $P$. parasitica contain significantly fewer but larger cells than those of the Albemarle leech. Each salivary gland of P. parasitica contains on the order of only 50 cells, typically $175 \mu \mathrm{m}$ in diameter, but up to $385 \mu \mathrm{m}$. Those of the Albemarle leech are much more numerous but smaller, typically up to only about 100 $\mu \mathrm{m}$. The posterior gland of $P$. parasitica is 'squatty' and confined to its segment, extending only to just beyond g. X, whereas the posterior gland of the Albemarle leech may be elongated posteriorly and extends as far as XI/XII.

\section{Tuberculated versus non-tuberculated Placobdella: developmental divergence}

The Albemarle turtle leech differs from the outgroup species P. parasitica in that the dorsum of the former bears characteristically prominent tubercles, whereas the dorsum of the latter is comparatively smooth (PP-4a). However, this generally accepted distinction is misleading in that the hatchling of $P$. parasitica more closely resembles the Albemarle leech in tuberculation than it does its own adult. In fact, the hatchling of $P$. parasitica reveals a closer phylogenetic relationship to the Albemarle leech than is evident from the adult alone.

The configuration of tubercles in the Albemarle leech persists throughout life, from hatchling to the fully mature adult (Fig. 12). In this study it was discovered for the first time that the hatchling of $P$. parasitica also has dorsal tubercles but they disappear with maturation. The hatchling of $P$. parasitica bears distinct tubercles arrayed in longitudinal rows in intermediate position on the a2 annulus in at least segments XIII-XXII, inclusively (PP-4b, 6.0 $\mathrm{mm}$ ). Interestingly, these tubercles align near the tips of the respective crop caeca, a feature seen in young and adult Albemarle leeches (Fig. 15). The early juvenile of P. parasitica still displays discernible tubercle-like protuberances in intermediate position on the a2 annulus in segments IX-XXIV, inclusively, but these are typically within creamcoloured spots (PP-3, $12 \mathrm{~mm}$ ). The integrity of these tubercles disappears with further maturation but the spots persist and may become extensively modified in the adult.

In the context of this taxonomic paper, the disappearance of tubercles during maturation in $P$ parasitica corroborates the diagnostic importance of the steadfast persistence of tubercles in the Albemarle leech.

Diagnosis of the Albemarle turtle leech. Based on the foregoing analysis of external and internal variability, remarkably few characters can be considered specific to, i.e., diagnostic of, this species. Out of the anatomical minutiae of this study, the following three characters assume particular importance in that they occur in all post-hatching individuals of this species, and importantly are not found in any other species in the Outer Banks region. In other words, for the purposes of this paper the following are considered collectively to be taxonomically diagnostic of the Albemarle turtle leech:

1) PROBOSCIS COMPLEX: highly specialised, long tapering proboscis crooked at proximal end such that the respective ductules of the anterior and posterior salivary glands join a measurable distance from the base of the proboscis to form a clear and unmistakable common ductule (Figs. 4, 9A, 14, p, pb, sb);

2) TUBERCLES: dorsal tubercles arranged in 5-7 multilinear rows, specifically with intermediate and medial rows on a2 annulus, and paramedial rows on a3 annulus, such that together they form a flattened ' $\mathrm{W}$ ' configuration in each mid-body segment in strict correlation with underlying crop caeca (Figs. 3A, 6B, 7A, B, 12B, 15A, $\mathrm{B}, \mathrm{ti}, \mathrm{tm}, \mathrm{tp})$;

3) CROP CAECA: crop caeca with a distinctive branching pattern, specifically with a ' $W$ ' configuration in each mid-body segment (Figs. 6B, 15B, cc1, cc5).

It must be emphasized that this study deals exclusively with the turtle leech of the Outer Banks region, and that outside this region the above diagnosis may not be applicable, or requires modification.

\section{Description of the Albemarle turtle leech}

Other characters examined in this study further describe this species but are not considered diagnostic, for one of two reasons.

Characters not found in all individuals of this species. This category comprises variable traits which are not 
manifested in all individuals of this species, sometimes because of obfuscation with age. This includes mid-dorsal stripe (whether interrupted or continuous); accessory eyes; median white shields (basis of the interrupted dorsal stripe); longitudinal pigmentation (stripes) on dorsum or venter; configuration of ovisacs; formed caudal peduncle; and rare ability to swim in hatchlings. Some traits are taxonomically reliable only in the mature adult. This includes flat body shape; ratio of width of caudal sucker to body width; and ventral orientation of caudal sucker.

Characters found in all individuals of this species but not specific to it. A number of traits occur in all examined individuals of this species. This category includes traits manifested also in some other leeches in the Outer Banks region, notably the outgroup species P. parasitica, and therefore they are not specific to the Albemarle turtle leech: apical mouth; two pairs of compound eyes; placobdellid head pattern; metameric marginal pattern; lack of nuchal ring; pre-anal tubercles; annulation; location of male and female gonopores; bifurcation of ovisacs; seven pairs of crop caeca; six pairs of testisacs; two pairs compact salivary glands; one pair of saccular mycetomes in ventral floor; feeding on turtles; and average size at egg-laying 37 (28-45) $\mathrm{mm}$.

\section{Taxonomic status of the Albemarle turtle leech}

This study highlights the need to establish accurate boundaries between species of Placobdella by setting rigorous criteria for diagnosing a species so it can be distinguished more objectively from allied species. Unfortunately, broad gaps in our knowledge, especially in terms of phenotypic variability, obscure these boundaries in some cases. Thus, it remains a formal possibility that the Albemarle turtle leech is endemic to this ancient, resilient swampland.

On balance, however, the Albemarle leech is more likely allied to, or conspecific with, a species of tuberculated Placobdella already described. In this context possible candidates are two well known turtle leeches, namely the northern P. rugosa (Verrill, 1874) or its apparent southern counterpart P. multilineata Moore, 1953, both of which generally resemble the Albemarle leech in terms of pigmentation and other variable and superficial characters. Unfortunately, however, synonymy to either of these forms is problematical due to inadequacy of original descriptions from type material. In fact, these two species are inadequately distinguished from each other, especially with regard to diagnostic (invariant) criteria proposed in this paper.

Placobdella rugosa is widely distributed, variable and frequently common in the northern United States and adjacent parts of Canada (de Carle et al. 2017; Mack et al. 2019). This species has a tortuous taxonomic history which has now been convincingly stabilised (Moser et al. 2012). Fortunately, the latter study also redescribed P. rugosa from fresh specimens from the type locality of 'North Dakota', based apparently on a single dissection.

The Albemarle leech resembles the revised account of P. rugosa in two diagnostic characters as proposed in this study. Firstly, Moser et al. (2012) illustrate most of an exceptionally long proboscis, and unequivocally state that the ductules of the anterior and posterior salivary glands merge to 'form common ductule bundles at the base of the proboscis'. However, their proboscis is described as 'cylindrical' and 'blunt-tipped', rather than tapering to a narrow tip. Less subjectively, there is no indication that the proximal end of the proboscis is crooked, as is diagnostic of the Albemarle leech. Unfortunately, the configuration of the crop caeca is not illustrated nor discussed from type material. Secondly, the authors clearly illustrate in a living specimen that the dorsum has five longitudinal rows of tubercles (their 'papillae'), the largest being in intermediate position (their 'paralateral') on the a2 annulus, with a discernible 'W' configuration in a given segment. Understandably, this arrangement is not clear on the original syntype specimens as illustrated. Furthermore, in another study the tubercles on specimens identified as $P$. rugosa from Quebec appear to be generally more 'warty' in terms of size, location and abundance (Mark et al. 2019) than those on the Albemarle leech. Nonetheless, the taxonomic relationship between the Albemarle leech and P. rugosa is obviously close, but prudently awaits a more detailed study of $P$. rugosa in terms of invariant external and internal characters within a sizeable population from the type locality.

Placobdella multilineata was originally described from 'New Orleans', a warm-water, swampland remarkable similar to the biome of the Albemarle region, and quite different from that of $P$. rugosa. The former species has been widely reported throughout much of the southeastern states and elsewhere. However, in view of the taxonomic unreliability of variable and superficial characters demonstrated in this study such nominal identifications should be treated with caution.

The Albemarle leech resembles Moore's original account of $P$. multilineata in only one of the diagnostic characters as proposed in the current study. Specifically, the character which both forms are currently known to have in common is the eponymous multilinear rows of dorsal tubercles. Even here the resemblance is incomplete in that Moore denigrates the paramedial rows and does not specifically align the paramedials onto the a3 annulus, 
as defined in the Albemarle leech. Unfortunately, Moore makes no mention of the other two diagnostic characters proposed in the current study, i.e., the whip-like proboscis, and distinctive ' $W$ ' shaped crop caeca.

Furthermore, there are other apparent discrepancies between the Albemarle leech and P. multilineata as originally described, including details of annulation, dorsal tuberculation (paramarginals larger and more constant than paramedials), apparent absence of mid-dorsal white shields, and body size (up to $57 \mathrm{~mm}$ in the Louisiana leech, but only up to $45 \mathrm{~mm}$ in the Albemarle leech). Moore locates the female gonopore at XIIa1/a2 rather than at XIIa2/a3 in the Albemarle leech. The reproductive system is not described, apart from referring to the male gonopore as a 'conspicuous transverse slit'. The male gonopore of the Albemarle leech is typically reminiscent of a rudimentary cylinder. Unfortunately, Moore does not describe the proboscis nor salivary glands, apart from mentioning that the anterior pair is medial to the posterior pair. He does confirm the presence of a paired saccular mycetome ('oesophageal pouch') in the ventral floor, and that the eyes are positioned in a colourless area. In addition to paucity of details regarding the digestive tract, a major shortcoming in the original description of $P$. multilineata is failure to record adequately the extent of variability of both external and internal characters in a series of specimens from the type locality. Unfortunately, since its original description nearly seventy years ago, few studies have added to our taxonomic understanding of this species from the type locality itself. These include observations on variability of the dorsal stripe (Sawyer 1967, 1972) and of pre-anal tubercles (Moser et al. 2014b, fig. 1A).

In conclusion, the primary goal of this paper is a comprehensive description of the Albemarle turtle leech, with the view of distinguishing it from other species in the same region. The taxonomic relationship of the Albemarle leech to closely allied forms, specifically P. rugosa or P. multilineata, is more problematical and lies outside the scope of this paper for the reasons given. In view of habitat similarity and relative proximity of type localities the Albemarle leech is provisionally identified as $P$. multilineata, with considerable reservation pending further morphological study of these and other tuberculated Placobdella. Owing to the provisional status of this identification, this account of the Albemarle leech cannot constitute a much needed revision of the nominal species P. multilineata.

For clarity, no inference should be made from this study regarding the taxonomic status or identity of $P$. multilineata reported elsewhere in North Carolina and adjacent South Carolina by Sawyer \& Shelley (1976) until their diagnostic characters are re-evaluated. Finally, caution is advised in that a small random sample of the demonstrably variable Albemarle leech can be taxonomically very misleading in that they may key out to any one of several nominal species (Sawyer 1972; Moser et al. 2016). For example, a specimen from this study with apparent accessory 'eyes' (see Fig. 10, ae) in isolation could be mistaken for P. hollensis.

\section{Acknowledgements}

The author gratefully acknowledges Mark Essig of Johns Island, SC, for his role in the design and construction of the aluminium leech trap which proved so effective in collecting leeches in the Albemarle wetlands. I also thank Dan R. Sawyer of Elizabeth City, NC, for his contribution in collecting the Albemarle turtle leech from Pasquotank County, NC (PM 12, PM-13a-g, PM-22 and PM- 28). I also thank him and Christopher Meekins of Raleigh, NC, for their tangible assistance in field collecting in the Albemarle region over many years, and Lorna Sawyer of Hendy, Wales, UK, for Figure 6A. Carl Peters-Bond of Biopharm (UK) Ltd, Wales, gave invaluable logistical support and technical advice throughout this and related studies.

William E. Moser, Curator, Department of Invertebrate Zoology, Smithsonian Institution, Washington, DC, was instrumental in the deposition of voucher specimens of the Albemarle turtle leech in the USNM collections.

Danielle de Carle, Department of Ecology and Evolutionary Biology, University of Toronto, persuasively pointed out an affinity between the Albemarle turtle leech and Placobdella rugosa, as discussed in the text. Finally, the author gratefully acknowledges Alejandro Oceguera-Figueroa and two referees for their constructive input during the review process. 


\section{References}

Arias, A.M. \& Steventon, B. (2018) On the nature and function of organizers. Development, 145 (5), dev159525. https://doi.org/10.1242/dev.159525

Bradbury, S. (1959) The botryoidal and vaso-fibrous tissue of the leech Hirudo medicinalis. Quarterly Journal of Microscopical Science, 100 (4), 483-498. https://doi.org/10.1242/jcs.s3-100.52.483

de Carle, D., Oceguera-Figueroa, A., Tessler, M., Siddall, M.E, \& Kvist, S. (2017) Phylogenetic analysis of Placobdella (Hirudinea: Rhynchobdellida: Glossiphoniidae) with consideration of COI variation. Molecular Phylogenetics and Evolution, 114, 234-248. https://doi.org/10.1016/j.ympev.2017.06.017

Cooper, C.D. (2017) Insights from zebrafish on human pigment cell disease and treatment. Developmental Dynamics, 246, 889-896. https://doi.org/10.1002/dvdy.24550

Dubois, A. (2017) Diagnoses in zoological taxonomy and nomenclature. Bionomina, 12, 63-85. https://doi.org/10.11646/bionomina.12.1.8

Galtier, N., Nabholz, B., Glemin, S \& Hurst, G.D.D. (2009). Mitochondrial DNA as a marker of molecular diversity: a reappraisal. Molecular Ecology, 18 (22), 4541-4550. https://doi.org/10.1111/j.1365-294X.2009.04380.x

Kvist, S., Narechania, A., Oceguera-Figueroa, A., Fuks, B. \& Siddall, M.E. (2011) Phylogenomics of Reichenowia parasitica, an alphaproteobacterial endosymbiont of the freshwater leech Placobdella parasitica. PLoS ONE, 6 (11), e28192. https://doi.org/10.1371/journal.pone.0028192

Lafuente, E. \& Beldade, P. (2019) Genomics of developmental plasticity in animals. Frontiers in Genetics, $10,720$. https://doi.org/10.3389/fgene.2019.00720

Mack, J., de Carle, D. \& Kvist (2019) Prey, populations, and the pleistocene: evidence for low COI variation in a widespread North American leech. Mitochondrial DNA Part A, 30 (6), 749-763. https://doi.org/10.1080/24701394.2019.1634698

Manglicmot, C., Oceguera-Figueroa, A. \& Kvist, S. (2020) Bacterial endosymbionts of Placobdella (Annelida: Hirudinea: Glossiphoniidae): phylogeny, genetic distance, and vertical transmission. Hydrobiologia, 847, 1177-1194. https://doi.org/10.1007/s10750-019-04175-Z

Meyers, J.M. \& Pike, D.A. (2006) Herpetofaunal diversity of Alligator River National Wildlife Refuge, North Carolina. Southeastern Naturalist, 5 (2), 235-252. https://doi.org/10.1656/1528-7092(2006)5[235:HDOARN]2.0.CO;2

Moore, J.P. (1953) Three undescribed North American leeches (Hirudinea). Academy of Natural Sciences of Philadelphia Notulae Naturae, No. 250, 1-13.

Moser, W.E., Govidich, F.R., Oceguera-Figueroa, A., Richardson, D.J. \& Phillips, A.J. (2016) Subclass Hirudinida. In: Thorp, J.H. \& Rogers, C.D. (Eds.) Thorp and Covich's Freshwater Invertebrates: Keys to Nearctic Fauna. Vol. II. $4^{\text {th }}$ Edition. Elsevier Science, San Diego, pp. 244-259.

Moser, W.E., Richardson, D.J., Hammond, C.I. Govedich, F.R. \& Lazo-Wasem, E. (2012) Resurrection and redescription of Placobdella rugosa (Verrill, 1874) (Hirudinida: Glossiphoniidae). Bulletin of the Peabody Museum of Natural History, 53 (2), 375-381. https://doi.org/10.3374/014.053.0203

Moser, W.E., Richardson, D.J., Hammond, C.I. \& Lazo-Wasem, E.A. (2013) Redescription of Placobdella parasitica (Say, 1824) Moore, 1901 (Hirudinida: Glossiphoniidae). Bulletin of the Peabody Museum of Natural History, 54 (2), $255-262$. https://doi.org/10.3374/014.054.0203

Moser, W.E., Richardson, D.J., Hammond, C.I. \& Lazo-Wasem, E. (2014a) Redescription and molecular characterization of Placobdella hollensis (Whitman, 1892) (Hirudinida: Glossiphoniidae). Bulletin of the Peabody Museum of Natural History, 55 (1), 49-54. https://doi.org/10.3374/014.055.0104

Moser, W.E., Richardson, D.J., Hammond, C.I., Gotte, S.W. \& Lazo-Wasem, E. (2017) Distribution of Placobdella hollensis (Whitman, 1892) (Hirudinida: Glossiphoniidae). Comparative Parasitology, 84 (2), 165-168. https://doi.org/10.1654/1525-2647-84.2.165

Moser, W.E., Richardson, D.J., Hammond, C.I. \& Lazo-Wasem, E.A. (2020) Redescription and molecular characterization of Placobdella michiganensis (Sawyer, 1972) (Hirudinida: Glossiphoniidae). Bulletin of the Peabody Museum of Natural History, 61 (2), 97-102. https://doi.org/10.3374/014.061.0202

Moser, W.E., Richardson, D.J., McAllister, C.T., Briggler, J.T., Hammond, C.I. \& Trauth, S.C. (2014b) New host and distribution records of the leech Placobdella multilineata Moore, 1953 (Hirudinida: Glossiphoniidae). Journal of the Arkansas Academy of Science, 68, 163-166.

https://scholarworks.uark.edu/jaas/vol68/iss1/30

Palmer, W.M. \& Braswell, A.L. (2013) Reptiles of North Carolina. University of North Carolina Press, Chapel Hill, North 
Carolina, $444 \mathrm{pp}$.

Richardson, D.J., Hammond, C.I., Moser, W., Phillips, A.J., Lazo-Wasem, E.A. \& Barger, M. (2020) Molecular variation and biogeography of the common North American turtle leech, Placobdella parasitica. Bulletin of the Peabody Museum of Natural History, 61 (2), 83-95. https://doi.org/10.3374/014.061.0201

Richardson, D.J., Moser, W.E., Hammond, E.I., Lazo-Wasem, E.A., McAllister, C.T. \& Pulis, E.E. (2017) A new species of leech of the genus Placobdella (Hirudinida, Glossiphoniidae) from the American alligator (Alligator mississippiensis) in Mississippi, USA. Zookeys, 667, 39-49. https://doi.org/10.3897/zookeys.667.10680

Sawyer, R.T. (1967) The leeches of Louisiana, with notes on some North American species. Proceedings of the Louisiana Academy of Science, 30, 32-38.

Sawyer, R.T. (1972) North American Freshwater Leeches, Exclusive of the Piscicolidae, with a Key to All Species. Illinois Biological Monographs. No. 46. University of Illinois Press, Urbana, Illinois 154 pp. https://doi.org/10.5962/bhl.title.53881

Sawyer, R.T. (1986) Leech Biology and Behaviour. Oxford University Press, Oxford, 1065 pp.

Sawyer, R.T. (2010) America's Wetland. An Environmental and Cultural History of Tidewater Virginia and North Carolina. University of Virginia Press, Charlottesville, Virginia, 260 pp.

Sawyer, R.T. \& Shelley, R.M. (1976) New records and species of leeches (Annelida: Hirudinea) from North and South Carolina. Journal of Natural History, 10, 65-97. https://doi.org/10.1080/00222937600770061

Siddall, M.E., Perkins, S.L. \& Desser, S.S. (2004) Leech mycetome endosymbionts are a new lineage of alphaproteobacteria related to the Rhizobiaceae. Molecular Phylogenetics and Evolution, 30, 178-186. https://doi.org/10.1016/S1055-7903(03)00184-2

Solano, F., Briganti, S., Picardo, M. \& Ghanem, G. (2006) Hypopigmenting agents: an updated review on biological, chemical and clinical aspects. Pigment Cell Research, 19, 550-571. https://doi.org/10.1111/j.1600-0749.2006.00334.x

Sokolova, I. (2018) Mitochondrial adaptations to variable environments and their role in animals' stress tolerance. Integrative and Comparative Biology, 58 (3), 519-531. https://doi.org/10.1093/icb/icy017

Speiran, G., Wurster, F. \& Eggleston, J. (2015) The groundwater geochemistry of the Great Dismal Swamp, a peat wetland discharging to two mid-Atlantic estuaries, USA. Geological Society of America, 2015 GSA Annual Meeting, Baltimore, Maryland, 1-4 November 2015. Available from: https:/gsa.confex.com/gsa/2015AM/webprogram/Paper267381.html (accessed 24 September 2020)

Verrill, A.E. (1874) Synopsis of the North American fresh-water leeches. United States Fisheries Commission Report for 1872 73, Pt. 2, 666-689.

Whitman, C.O. (1891) Spermatophores as a means of hypodermic impregnation. Journal of Morphology, 4, 361-405. https://doi.org/10.1002/jmor.1050040307

Whitman, C.O. (1892) The metamerism of Clepsine. In: Festschrift zum 70 Gubertstage Rudolf Leuckarts. s.n., Leipzig, pp. 285-338. 


\section{APPENDIX}

Source material. Following are annotated locality records for the turtle leech collected in the Albemarle region by the author and Dan R. Sawyer (Fig. 1B). This compilation represents the source material for this taxonomic study. Specimens prefixed (PM) or (PP) are deposited in the Medical Leech Museum, Swansea, Wales, UK and those prefixed (USNM) are deposited in the Smithsonian Institution, Washington, D.C.

\section{ALBEMARLE TURTLE LEECH:}

\section{NORTH CAROLINA}

Chowan County. STUMPY CREEK, CANNON FERRY ROAD [36.278713, -76.665199]: PM-21a [12 May 2019, 1 adult, 32 $\mathrm{mm}$, dissected, laid 56 young].

Pasquotank County. GRIFFIN SWAMP ROAD, STREAM [36.200090, -76.174271]: PM-12 [13 May 2016, 1 adult, 44 mm, on beer bottle, dissected]; PM-13a-g [13-14 May 2016, 7 juveniles, varying states of feeding; PM-13c, 6.5 mm, dissected]. ELIZABETH CITY, PELICAN POINTE [36.267110, -76.190625]: PM-22 [11 June 2019, 50 mainly fed post-juveniles on carapace and plastron of snapping turtle Chelydra serpentina on land; sample of 7 collected]; PM-28 [1 May 2020, 1 adult].

Perquimans County. FERRY ROAD, NEAR LITTLE RIVER [36.191046, -76.284581]: PM-19 [1 May 2018, 1 brooding adult, $29.5 \mathrm{~mm}$, + 54 young, 4.5-5 $\mathrm{mm}$, on plastic, roadside ditch].

Tyrrell County, all in community of Gum Neck. DITCH NEAR FWB CHURCH, CULVERT AT TURNER ROAD [35.710761, -76.113023]: PM-1 [17-22 May 2011, 5 adults]. PM-1a [1 adult, 44 mm, + 28 young], PM-1b [1 adult, 36 mm, dissected]; PM-1c [1 adult, 40 mm]; PM-1d [1 adult, 41 mm]; PM-1e [1 adult]; PM-5 [21 March 2012, 27 mm]; USNM 1190084 [17-22 May 2011, 4 juveniles, culvert near Gladys Sawyer home (35.717592, -76.116156)]; USNM 1190082 [17-22 May 2011, 26 juveniles, isolated muddy puddle below culvert]. 460 GRAPEVINE LANDING ROAD [35.719759, -76.107886]: PM-4 [10-23 Oct 2013, 1 adult, 39 mm, dike canal]; PM-6 [1 brooding adult, $32 \mathrm{~mm},+30$ young, dike canal]; PM-15cd [24-26 Apr2017, 2 brooding/gravid adults, 45, 37 mm, dike canal]; PM-15e-h, 332 embryos; PM-18 [22 May 2018,1 adult, escaped, + 2 juveniles, dike canal]; PM-23 [17-28 May 2019, 12 juveniles, 5.3-20.2 mm]; PM-26 [17 May 2019 , 1 juvenile, 8.3 mm, axil of Florida cooter, Pseudemys floridana, on land]; PM-27 [25 May 2019, 1 freshly fed juvenile, sacrificed for blood smears]; USNM 1193656 [May 2008, 1 sub-adult, on snapping turtle Chelydra serpentina, on land]; USNM 1190083 [17-22 May 2011, 2 juveniles, dike canal]. STEPHEN'S RIDGE, EDGE OF SWAMP [35.721446, 76.101951]: PM-14a-d [25-30 Apr 2017, 3 gravid adults, 45, 35, 28 mm, + 1 pre-adult, 15.5 mm]; PM-15a-b [24-26 Apr 2017, 2 brooding/gravid adults, 39, 42 mm]; PM-17 [20-21 May 2018, 1 adult, 34 mm, + 5 juveniles, 7.8-14.2mm]. STEPHEN'S RIDGE, JONES POND [35.724137, -76.101361]: PM-2 [19 May 2016, 3 juveniles, 9-10 mm]; PM-3 [15 May 2016, 1 adult, 30 mm, inside plastic bucket]; PM-24 [19 May 2019, 4 transparent juveniles, 8.0 mm, on neck of mud turtle Kinosternum subrubrum on land]; USNM 1190085 [17-22 May 2011, 1 juvenile]. COOPER CORNER [35.712759, -76.114115]: PM-16 [7 May 2017, 1 juvenile with blood, seepage area above culvert]; PM-25 [22 May 2019, 1 juvenile, $8.1 \mathrm{~mm}$, small stream below culvert].

Washington County. PETTIGREW STATE PARK, LAKE PHELPS, VEGETATED SHORELINE NEAR LANDING [35.790044, -76.410975]: PM-7 [6 May 2016, 1 adult, 33 mm, on submerged log]; PM-8 [6 May 2016, 1 adult, 35 mm, dissected, on submerged log, under bark]; PM-9 [12 May 2016, 1 brooding adult, $31 \mathrm{~mm},+15$ young, on submerged log]; PM-10 [12 May 2016, 1 gravid adult, 31 mm, on submerged log]; PM-11 [12 May 2016, 11 juveniles, in axils of snapping turtle Chelydra serpentina on land, at landing].

\section{VIRGINIA}

City of Virginia Beach. BACK BAY NATIONAL WILDLIFE REFUGE, LOTUS GARDEN PARK, SANDBRIDGE ROAD [36.731212, -75.984371]: PM-20 [22 June 2018, 1 juvenile with blood, $10.6 \mathrm{~mm}$, on plastic container]. 


\section{NORTH CAROLINA}

Tyrrell County. GUM NECK, NEAR FWB CHURCH [35.712480, -76.114413]: PP-1 [26 May 2017, 1 recently fed specimen, on snapping turtle, Chelydra serpentina, on land, $36.5 \mathrm{~mm}]$. GUM NECK, 460 GRAPEVINE LANDING ROAD [35.719759, -76.107886]: PP-2 [3 May 2018, 1 specimen with some blood in gut, on mud turtle, Kinosternum subrubrum, on land, $22.0 \mathrm{~mm}$ ]; PP-3 [10 Oct 2013, 1 unfed specimen, on aluminium trap, $12.8 \mathrm{~mm}$ ]; PP-4a [27 May 2019, 1 brooding adult with numerous hatchlings on belly, on aluminium trap, $39.8 \mathrm{~mm}$ ]; PP-4b [hatchlings of PP-4a]. 